\title{
Essay One: Blogs and the megaphone effect
}

\section{with Barbara J. Phillips ${ }^{1}$}

THE MEGAPHONE - CULTURAL CAPITAL - A Point of BeginningClass Tastes Versus Cultural Capital-The Vicissitudes of Cultural CapitalBeyond Habitus - THE FORMS OF CAPITAL - Metaphor or Theory?-How many Capitals?-Metaphor Run Amok-Another Rival: Human CapitalWhat is Cultural Capital?-TASTE AND CULTURAL CAPITAL-What is Taste? - Taste Goods - Two Meanings of Taste - Consumer Taste LevelsGoffman on Audiences-EMPIRICAL EVIDENCE-Method in Consumer Sociology_Findings: Blogger Trajectory-Findings: Blogger OutcomesFindings: Maintaining an Audience-DISCUSSION OF FINDINGS Bourdieu on the Web-Ideology of Giftedness-LIMITATIONS-Not All Goods Are Taste Goods - Consumer Culture, Consumer Sociology

The Web allows ordinary consumers to reach a mass audience, to grab hold of the megaphone. More consumers have more opportunities to reach thousands of other consumers than ever before. I draw on Turner's (2010) idea of a demotic turn, to situate fashion blogs as one way in which ordinary consumers get a megaphone. I then delve into Bourdieu's idea of cultural capital to explore how a few consumers succeeded in realizing the potential for a mass audience. Fashion blogs yield new insight into the meaning of cultural capital, one of Bourdieu's most original and subtle ideas, and a gateway to viewing consumers through a sociological lens.

\section{THE MEGAPHONE}

Among the first fashion bloggers to grab the megaphone was a 13-year-old girl (Rosman 2009); by 2010 this blogger had been profiled in the Wall Street Journal, the Guardian, and other publications, and her blog posts were read by tens of thousands. This blogger got hold of the megaphone by means of her actions, not by birth or through institutional position. 
The megaphone is not bound to the fashion context. Chocolate and Zucchini is a food blog whose author was not trained as a chef and did not work for a food magazine before starting the blog. Her posts may receive more than 100000 views. Tight Ass Little Apartment is a blog about interior design and home decor. This blogger was not trained in design or employed as a designer before she started the blog.

The megaphone effect occurs when ordinary consumers, defined as people lacking professional experience and not holding an institutional or family position, post to the Web about consuming, with the potential to acquire a mass audience. The blog posts of interest deal with consumer goods: fashion, food, home décor. Consumer bloggers achieve an audience that in the past was only available to institutionally located professionals (McCracken 1986). Consumers achieve this audience by means of publicly consuming: choosing, evaluating, and engaging with clothing (in the focal example for this essay), and posting accounts that may be read by a large audience of strangers.

This new consumer action, made possible by the Web, has not been explained. By 2010, anyone who wished to share their thoughts with others could do so on Facebook. When someone chooses instead to reach for a mass audience of strangers, this action can't readily be labeled as sharing (Belk 2010; Giesler 2006). The fashion bloggers studied mostly don't display clothes they sewed by hand, but mass-marketed, branded goods; likewise, food bloggers do not only show meals cooked from scratch, and online reviewers do not only write about craft breweries and artisan bakeries. Hence, consumer blogging can't readily be understood as prosuming (Campbell 2005). You could label it electronic word of mouth and call these bloggers opinion leaders or market mavens (Kozinets et al. 2010; Feick and Price 1987), but this obscures what is new and different: ongoing posts, by ordinary consumers, directed at a mass audience of strangers. Box 1.1 develops in detail what fashion blogs are not.

Turner (2010) provides a conceptual framework that can locate the megaphone effect. He points to a larger cultural movement, the demotic turn, which embraces talk radio and reality television, as well as online behavior. The demotic turn occurs when ordinary people get more opportunities to appear in the media, relative to some baseline, which I will locate in about the 1959-1995 period. ${ }^{2}$ That baseline period, as argued in my Introduction to this book, represents the full flowering of consumer society in the United States. During this period, conventional mass media flourished: it was the age of broadcast and then cable television, before the advent of the Web shattered the dominance of television and opened up the mass media. The 1959-1995 period can also be described as the apex of the movement toward a consumer society, which dates back to the Industrial / Scientific / 


\section{BOX 1.1 WHAT FASHION BLOGS ARE NOT}

Blogs marked one of the first instances of Turner's (2010) demotic turn, taking off early in the 2000s, well before Yelp or Pinterest. In early accounts, blogging allowed consumers to become producers, or prosumers (Beer and Burrows 2010; Campbell 2005; Reed 2009). Digital prosumers were thought to share information with the aim of building online communities (Firat and Dholakia 2006; Hodkinson 2007; Jarrett 2003; Schau et al. 2009). This viewpoint, that blogs acted as personal diaries online (Hodkinson 2007), connects with Belk's (2010) ideas about sharing. Blogging may be approached as "sharing out," intended to expand one's community of intimates, in contrast to "sharing in," where the motive is to tighten existing bonds.

In the early 2000s, blogging was also seen as a hallmark of Web 2.0, proposed as a more democratized and participatory phase in the evolution of the Internet. With Web 2.0, it was prophesied, user-generated content, experienced as more authentic and personal, would overwhelm content generated by traditional power centers such as marketers and publishers (van Dijck 2009). Bloggers, as consumers, could now co-create the meanings of the brands, rather than passively absorb meanings engineered by established, authoritative culture makers (Holt 2002; cf. McCracken 1986; Zwass 2010). The Web was on the frontier of co-creation, as individuals devoted long hours to creating content without pay (Ritzer and Jurgenson 2010). Yet, prosumption and co-creation were also criticized as doubly exploiting consumers through the capitalist system (Cova and Dalli 2009; Zwick et al. 2008), because prosumers are not paid, yet create value for a company or brand.

Some studies based on interviews found that bloggers posted to express their own identity and point of view (Hodkinson 2007); they write for themselves, as an archive of their own thoughts and feelings for later reconsumption (Reed 2009). This matched findings from interviews with non-digital prosumers (for example, craft consumers such as amateur carpenters, chefs, and quilters) who desire to engage in creative acts of self-expression (Campbell 2005). Craft consumers are concerned with the possible alienating and homogenizing effects of mass market goods; in a postmodern vein, they focus on authenticity and resistance to mass culture (Campbell 2005). Likewise, digital prosumers were thought to pursue empowerment and emancipation (Firat and Dholakia 2006; Jarrett 2003; Schau et al. 2009). To synthesize early ideas: blogging consists of personal disclosures made in the pursuit of an identity project, aimed at forging community bonds between blogger and followers, with the hope of emancipating from the market.

These views of blogging, which dominated consumer research when I started thinking about consumers online, yield predictions about fashion blog content. First, if blogging is about authenticity and emancipation, accepting free goods and flogging them on one's blog should be controversial, and liable to stress both the blogger's self-concept and community bonds with readers. Kozinets et al. (2010) found this type of stress among bloggers given a free cell phone and invited to blog about it. Second, because blogging is about emancipation from the marketplace via prosuming, you would expect branded goods to be de-emphasized in blog posts, especially popular mainstream brands. In fashion blogs, you would expect thrift store chic to be mandatory, store-bought clothing rare, and conventional designer 
brands absent. Third, because blogging empowers, then in addition to avoidance of mass-market brands, you also would expect active resistance to and criticism of commercial goods, advertising messages, and marketing efforts (Shankar et al. 2006). Fourth, because blogging is sharing (Belk 2010) and sharing involves reciprocity, comments on blog posts by readers should often take the form of sharing back, in which readers reciprocate by sharing details of their own personal lives, so that bloggers and readers together build community. Finally, because blogging is fundamentally about creating online community, the relation between blog posts and reader comments should be dialogic, akin to what is seen in peer-to-peer networks and discussion forums (Mathwick et al. 2007; Schau et al. 2009).

None of these predictions were borne out. What fashion bloggers do is new and different.

Technological / Capitalist Revolutions (Campbell 1987; Gronow 1997; McCloskey 2010; Muller 2007).

Continuing with Turner's (2010) thesis, during the baseline period only media professionals, other occupants of powerful institutional positions (for example, government officials or business leaders), and designated celebrities could appear on television or otherwise gain a mass audience. Moreover, celebrities became that way by successful performances in credentialed institutional settings (entertainment, sports, and so on). Until very recently, ordinary people lacked access to the mass media and could only gain that access by successful performance in some institutional setting, however extraordinary their motivation or skill. From this perspective, an ordinary person is defined precisely by the absence of institutional credentials.

These restrictions began to loosen with the spread of reality television. Here the media began to create celebrities, rather than mediate between existing celebrities and the mass audience. Turner (2010) notes, however, that the celebrity gained by reality television participants is not gained by their actions nor even owned by them (his discussion of exploitative contract terms is bracing). Reality television celebrity remains an institutionally mediated outcome in which the owners of mass media select the citizens who are to be granted a mass audience.

The megaphone effect is distinctive within the larger context of Turner's demotic turn, because in the consumer sphere, people are now able to grab the megaphone for themselves, without institutional certification. Unlike reality television participants, who must satisfy a casting call controlled by professionals, a successful blogger gains her audience directly: she blogs in such a way that many other consumers begin to follow her posts. Once a consumer gains a mass following, this audience can be converted into institutional access, and further leveraged. But institutional mediation is no longer required to gain a mass audience. That is new. 
However, most bloggers never gain a big audience (Lovink 2008). How did a few fashion bloggers succeed in realizing the newfound possibility to build a mass audience? What's special about them? This essay offers a sociological explanation centered on taste judgments and the accumulation of cultural capital (Bourdieu 1984, 1986 [1983]). To explore the meaning of cultural capital takes me on a lengthy detour away from fashion blogging. But as noted in the Introduction, this book is not primarily about blogging, Yelp or Pinterest. It aims to launch a consumer sociology. Cultural capital is central to that enterprise.

\section{CULTURAL CAPITAL}

Bourdieu's signature idea is refractory and elusive. What makes it difficult is, first, that Bourdieu designed his prose to be difficult (see Box 1.2). Cultural capital is difficult, second, because Bourdieu's thinking is supple and innovative; and third, because his thinking on this topic did not stand still. What Bourdieu meant by cultural capital early in the 1960s is not the same as what he meant by it later in the 1980s; and by his death in 2001, the term had almost disappeared, scarcely present in his posthumously published "not an autobiography" (Bourdieu 2008). It was not in Bourdieu's interest to admit that cultural capital ever meant anything other than what he meant by it that day, for the occasion at hand. Its mutations and divagations have been left tacit, even as it has accreted unhelpful meanings in the hands of later scholars.

A novel take is made even more difficult, because cultural capital has become an encyclopedia entry, a highlighted phrase in a textbook, a commonplace in the rhetorical sense. Bourdieu's most famous book, Distinction (1984), has been cited more than 30000 times as this is written, and based on my haphazard checks since 2010, its citation count continues to mount by thousands per year. Everybody already knows what cultural capital means, and the term can be tossed off by historians and social scientists across diverse fields in confidence that the audience will get it (see, e.g., Lanham 2006a; Muller 2007; Wickham 2005). As I will try to show, that confidence is misplaced; often what the audience gets is not what Bourdieu meant, but just some fragment of conventional wisdom, of the sort Bourdieu spent his life inveighing against.

And yet, despite the thousands of muddied citations and its diffusion through literate circles, cultural capital remains the glittering, oddly shaped shell that draws the eye on the beach because nothing like it was there yesterday. Cultural capital continues to be an unfamiliar and unconventional idea, if only because it is a sociological term of art, and sociology remains terra incognita for scholars in the behavioral and social sciences. You could 


\section{BOX 1.2 BOURDIEU'S PROLIX PROSE}

Bourdieu wrote in a style alien to behavioral science journals in the Anglo-Saxon world. Here is a pertinent example from Distinction (1984, p. 256), describing practices of those high in socio-economic position:

Verbal virtuosities or the gratuitous expense of time or money that is presupposed by material or symbolic appropriation of works of art, or even, at the second power, the self-imposed constraints and restrictions which make up the "asceticism of the privileged" (as Marx said of Seneca) and the refusal of the facile which is the basis of all "pure" aesthetics, are so many repetitions of the master-slave dialectic through which the possessors affirm their possession of their possessions. In so doing, they distance themselves still further from the dispossessed, who, not content to being slaves to necessity in all its forms, are suspected of being possessed by the desire for possession, and so potentially possessed by the possessions they do not, or do not yet, possess.

This sentence is representative of Bourdieu's writing style in length, syntactical complexity, and embedded historical allusions (that is, to the Stoics, Kant, Hegel, and Marx). The sentence ends in a complex rhetorical figure, in this case antanaclasis, the repetition of the same word in multiple senses ("business is business" would be a familiar example in English). This antanaclasis to the ninth degree is typical of Distinction: it is full of rhetorical figures.

To hear Bourdieu tell it, he wrote in this rhetorically stylized way because cultural sociology, to advance, had to "make the familiar strange" (1984, pp. xiv, 227; Bourdieu and Wacquant 1992, p. 169). Bourdieu believed that sociological facts were systematically misrecognized, and his rhetoricized prose attempts to slow down the reader, to provoke her, to make her engage the motivated misrecognition of social facts.

Billig (2013) provides an alternative, and less supportive account, of why Bourdieu wrote as he did. Either way, the passage quoted should place the reader new to Bourdieu on alert. His ideas, such as cultural capital, are difficult, and his prose style doesn't help.

Finally, this passage highlights a common misunderstanding of cultural capital. It is a deadly error to mistake knowledge or education for capital. For example, not all readers will have recognized the tacit references to Kant and Hegel in the quoted passage. Does that mean you lack cultural capital, relative to Bourdieu? In parallel, Kingston (2001, p. 97, n. 2), confronted with the unknown word "glissando" in the title of Lamont and Lareau (1988), laments how his incomprehension exposes his own lack of cultural capital, relative to theirs.

But this usage of cultural capital is not correct. Whether you recognize glissando depends on how much education in music you had. Whether you linked "master and slave dialectic" to Hegel and "pure" to Kant depends on your knowledge of 18th and 19th century Continental philosophy. Knowledge of cultural products is not cultural capital. Education means education, not cultural capital, and certainly not educational capital, a lapse to which Bourdieu was all too prone.

Later l'll show how fatal this confusion can be to Bourdieu's project. To use cultural capital as a catchphrase for knowledge or education throws away victory to Becker (1993), in his contest with Bourdieu. 
go through an entire PhD program in psychology in the 1980s, and never encounter the term (I did).

The challenge is how to convey the idea of cultural capital to those unfamiliar with it, so that it can be applied to fashion blogging, while simultaneously setting up a critique, both of misunderstandings and of outmoded senses of it, so that it can be renewed to illuminate new things consumers do online. By the time I am finished, it may not be Bourdieu's idea any more, but only my own concoction. Nonetheless, he will remain at least its father, and I think it fit to acknowledge that paternity, even if I may not lay claim to his patrimony.

Not everyone working in sociology is so enamored of cultural capital (e.g., Lamont 1992, 2010). Younger scholars do well to remember that cultural capital remains a controversial idea, a bold conjecture worth considering, as Sir Karl Popper might have said, but possibly, one already found to be scientifically wanting, and ossifying into cant. Not everyone thinks it provides a correct or even useful take on social success (Goldthorpe 2007; Hennion 2010).

To anticipate what follows, I will first point to a misunderstanding of cultural capital, that has to be bracketed and set aside, and then discuss two legitimate but quite different senses of cultural capital, now in circulation, only one of which is helpful for studying new things consumers do online. To further complicate the picture, I will introduce two rival ideas which vie with cultural capital, and which, if accepted, would make it unnecessary to ever speak of cultural capital any more. I will hammer cultural capital, using these rivals, to temper it and sharpen the cutting edge.

The misunderstanding is to collapse Bourdieu into Veblen, and mistake social position, and behaviors that come with it, for cultural capital. The two legitimate senses correspond to the static and dynamic operation of cultural capital; in metaphorical terms, to its rentier and capitalist aspects. Only the dynamic meaning is suitable for exploring what consumers do online. And the two rivals that must be let into the ring are boundary drawing, per Lamont (1992), and the human capital beloved of Becker (1993), and still prominent in rational choice theory (Ratchford 2001).

The goal of these next sections is clarification and purification, achieved through a trial by fire. Cultural capital risks a slow death from conceptual arteriosclerosis, but is worth the effort to beat into shape.

\section{A Point of Beginning}

Bourdieu's thinking about cultural capital evolved. This evolution is best grasped by returning to one of his early accounts of cultural capital, given in Bourdieu and Wacquant (1992, p. 160), and then, articulating 


\section{BOX 1.3 BOURDIEU THE POLEMICIST}

Bourdieu became a skilled polemicist, not bound by the politeness conventions of American academia, and not constrained by journal peer review and its narrow culling to a hedged and pallid norm. Here is an example:

I was reacting no less against the microphrenic empiricism of Lazarsfeld and his European epigones, whose false technological perfection concealed an absence of any real theoretical problematic ... One needs to take into account the whole effect of domination by American science ... [and its] inadequacies and technical mistakes ... in which segments of experience aping experimental rigour conceal the total absence of a real sociologically constructed object. (1990, pp.19-20)

These are not the fiery words of a young Turk: Bourdieu was well into his fifties. The quote is not an isolated instance, nor did Bourdieu mellow with age. See Bourdieu (2008, pp. 72ff.) for another assault on Lazarsfeld, and Bourdieu (2005, p. 2) for a reference to the "flabby" ideas of Becker (1993).

There was no coming to terms with Bourdieu's work while he was alive; he was tenacious in defending his turf. Only now can we sort through it, to find the seed and discard the chaff. But what a garden of delights, despite its rank wildness!

the criticisms that led Bourdieu to move on. Wacquant was chosen by Bourdieu to receive his mantle and carry forward his legacy (if I have read Lamont 2010 correctly). Their book takes the form of a sympathetic interview, a format that allowed Bourdieu to speak in a more accessible style about his ideas. As Box 1.2 shows, Bourdieu's own writings were not always so accessible.

However, we cannot take what is written in Bourdieu and Wacquant (1992) as an accurate transcription of what Bourdieu actually thought decades earlier. Rather, the 1992 account shows how Bourdieu wanted us to think about his thinking, with an eye to securing his legacy. We must approach Bourdieu's remarks as rhetorically structured comments, designed more to draw the reader to his side, than to provide historical insight (see Box 1.3).

Bourdieu writes that he developed the idea of cultural capital "in the early sixties to account for the fact that, after controlling for economic position and social origin, students from more cultured families not only have higher rates of academic success but exhibit different modes and patterns of cultural consumption and expression in a wide gamut of domains" (emphasis added). Now put this formulation in context: Parisian society, 50 years ago. To illustrate, let Alain and Jean attend the same preparatory 
school. Set their family income and fathers' level of education to be the same, and assume each grows up in a large apartment in a good Parisian neighborhood. In terms of conventional indicators, we've told a story that places Alain and Jean on a par with respect to socio-economic position.

Bourdieu's contribution was to assert the potential significance of one difference that might still separate these two youths. Suppose further that Alain grew up surrounded by paintings and sculpture, and had a piano in the house, on which he learned to play classical pieces; while in Jean's case, money was spent on furnishings and high-end appliances, and the music heard was popular songs on a phonograph.

Bourdieu's thesis was that because they differed in the cultural goods consumed (a wonderful black box of a term, which will later need to be unpacked), Alain would grow up endowed with a greater amount of cultural capital, and that this endowment would give Alain an advantage over Jean in multiple social contexts. Because of the centrality of aesthetic judgment in the French elite schools of that era (Bourdieu 1996), Alain's endowment would lead to better performance in prep school, and a head start in acquiring a high socio-economic position. Specifically, Alain's capacity to exercise taste in cultural activities, of the sort expected and respected among fellow Parisians who already held a high socio-economic position, would enhance Alain's own life trajectory.

This definition of cultural capital is an early formulation, or at least, is distinct from others found in Bourdieu's work. It nonetheless illuminates how Bourdieu's thinking differed from that of Theodore Veblen and other sociologists. It provides a prophylactic against the key misunderstanding of cultural capital: to mistake it for an afflatus of social position. The second phrase in the quote lays it out: that "after controlling for economic and social position" there was still a difference between Alain and Jean. That is, after equating the socio-economic position of two families at a high level, in the Paris of that era, you could find yet a further systematic way to separate families, which would predict how their offspring would follow different social trajectories. One set of families possessed a form of wealth not present in the other: a wealth of culture.

\section{Class Tastes Versus Cultural Capital}

This first quote makes cultural capital sound straightforward enough. Nonetheless, the selected quote provides a radical perspective on Bourdieu's thinking, given the frequency with which this definition has been ignored in empirical efforts to study cultural capital. Holt's (1998) study - and let me first acknowledge that Holt did more than anyone else to recapture Bourdieu for consumer research - is illustrative. In a small college town, 
Holt interviewed two polarized samples, comparing the top quintile, in terms of father's education and occupation, to the bottom quintile, also in terms of father's education and occupation. In short, he compared the scions of college graduates to those of manual laborers.

Holt's sampling strategy, based on selecting polarized social positions, was subsequently applied in consumer research by Berger and Ward (2010), Bernthal et al. (2005), Henry (2005), and Üstüner and Holt (2010), and I believe, has been frequently applied elsewhere in the social sciences. Schematized, you first pick two groups of people who occupy very different social positions, one high and one low. Second, you survey broadly their habits and preferences, to find where the two groups differ. Last, you take the preferences and habits that distinguish the high group, and label these as signs of an abundance or deficit of cultural capital. Done.

Now suppose Bourdieu had executed a similar sampling strategy back in Paris. He would have compared a sample of Alains and Jeans from the wealthy 16th Arrondissement, to a sample of Mohammeds and Sachas from a poor banlieue out in the sticks. He did not do that. Such a sampling strategy would conflate cultural capital with, rather than control for, economic and social position (and ethnic and urban versus rural differences). Any sample that draws from polarized social and economic positions, and then attributes cultural capital to the high group, is going to submerge cultural capital proper-Bourdieu's innovative take on how social position reproduces across the generations - into the more conventional sociological idea nicely captured in Goffman's (1951, p. 301) term, "restrictive practices." And that merged (nay, mongrel) idea will no longer capture Bourdieu's unique insight.

Goffman's (1951) earlier account emphasized the potential for faking, and the need to police wishful or fraudulent claims to a high status. A restrictive practice is a defensive maneuver, designed to prevent entry by the undeserving and ineligible. Bourdieu recognized, I believe, that taste judgments in the realm of art and music, in the Paris of that era, provided the urban, educated upper middle class with such a restrictive practice. (One can find friendly comments about Goffman scattered through Bourdieu's work.) Only persons surrounded by objects of high culture from birth, and engaged early in mandated forms of cultural production, such as playing classical piano music, were likely to succeed in making, reflexively and without effort, the aesthetic judgments required to be accepted among others holding high social position. In this telling, cultural capital is an endowment obtained from the family, manifest in tastes for one type of cultural product over others.

To update Goffman's account, and tease his notion apart from Bourdieu's, note that restrictive practices can be used, not only to rebuff claims to high social status, but also to test and check claims to in-group 
status, for any group, whether high or low in social position. And restrictive practices need not involve cultural products, or even tastes. The underlying sociological insight has been developed most fully by Michele Lamont (1992): members of social groups must draw boundaries. External boundaries control membership in the group, and hence are most salient in the case of voluntary associations, subcultures, and similar groups scattered through the vast middle of a developed society like the United States. If you want to be accepted by Harley-Davidson owners, you may have to speak a certain way, wear particular clothing, and kit your bike one way not another. To be accepted as a hipster, rather than a wannabe, likewise requires visible practices (Arsel and Thompson 2011).

Oftentimes, taste judgments are the restrictive practice that controls group membership. You won't be accepted by other members of the group if you don't give signs that you share their tastes. Holt (1998) gives numerous examples of consumer taste practice; Arsel and Thompson (2011) and Thornton (1996) describe ridicule, by in-group members, directed at failed attempts by out-group members to display the proper taste; and Berger and Ward (2010) and Elliott and Davies (2006) discuss articles of clothing that signal shared tastes.

However, boundary-drawing, as studied by Lamont (1992), and taken as an extension of Goffman's (1951) ideas about how groups police membership, has little to do with cultural capital, defined in shorthand as that new idea Bourdieu had. Lamont (2010) is firm that her thinking about group boundaries does not build on or require Bourdieu's idea of cultural capital. Group boundaries, and the use of taste as a practice to control group acceptance, are bona fide sociological ideas, which are not alien to the broader corpus of Bourdieu's thinking. But the meaning of cultural capital - that new idea-has to be sought elsewhere.

Re-reading Bourdieu (1984) may not help in this quest. Bourdieu deliberately plays on the two meanings of distinction throughout Distinction, making this word refer sometimes to difference and boundary, while at others to elevation and prestige. To keep the two meanings straight, I will refer to distinction-between versus distinction-over. Distinction-between draws boundaries, creates groups, and fosters solidarity. It operates locally and acts to cluster like-minded individuals and sequester them from others with different tastes. Distinction-over asserts preferment, sustains hierarchy, and elevates one above others. It operates at the societal level and can raise select individuals to prominence. Rather than grouping peers together into an Us apart from a Them, taste, when it underwrites distinction-over, acts to elevate a few relative to the many.

Prior accounts in consumer research have successfully imported Bourdieu's account of taste aimed at distinction-between, and developed 
how taste can be pressed into service as a boundary marker between groups, to promote affiliation and community (Holt 1998; Arsel and Thompson 2011). Put another way, much past consumer research on taste has followed Lamont (1992), while trying to lay claim to the patrimony of Bourdieu by means of incessant references to capital. After all, Bourdieu (1984) has been cited 20 times as often as Lamont (1992), which counts for a lot, in the scholarly search for authority. But the gap that separates Lamont from Bourdieu is huge, and blurring the difference can only obscure what we seek to study.

What separates the distinction-between of Lamont, from the distinctionover implied by references to capital, is the democratic character of drawing boundaries. No elite position, and no unusual heap of resources, is required to draw boundaries. People at all levels of society draw boundaries that include espoused others and exclude shunned others. It's just what people do, every day and automatically. Groups low in the pecking order mark out their boundaries just as enthusiastically, and with the same deadly seriousness, as highly ranked groups. Groups not ranked, as with so many voluntary groups in the United States, are just as concerned to draw the line as an English nobleman. Boundaries construct identity and promote affiliation with like-minded others, which reinforces identity, which makes it easier to see with whom one might affiliate. No capital of any type - no wealth - is required.

To summarize: cultural capital must have something to do with distinction-over, but must not be conflated with socio-economic level. It is hard to keep this straight. Individuals who amass cultural capital get elevated, and people endowed with cultural capital tend to stay elevated; but sampling from a group of people who already have elevated socioeconomic status, defined in conventional terms as falling at the high end of the income, wealth, occupation, and education distributions, does not secure insight into cultural capital. If Bourdieu's initial definition is correct, as embodied in my Alain and Jean example, some people with high income and good position possess lots of cultural capital, while others do not. Sampling on socio-economic level does give insight into the restrictive practices used by the elite of that time and place. Sometimes these restrictive practices rely on cultural products, but they need not. In Paris in the 1960s, art and music served that goal; for the senatorial elite in the late Roman Empire, the ability to compose fine Latin verse served that purpose (see Wickham's 2005 discussion of Sidonius Apollinaris). For the American elite of the early 2000s - hedge fund honchos perhaps - neither art, music, nor verse need be central to the restrictive practices in use. Sheer gobs of money, or gigantic homes nobody else can afford, may do the trick. Restrictive practices and cultural capital are separate sociological ideas, which are sometimes found intertwined and sometimes separate. 
In metaphor: low social position is a sink filled from many a slough, gutter, swale, and pipe. You cannot dip a cup and say, "this bit came down that pipe." High social position is a forest canopy, reached by vine and trunk, monkey and moth. Running a scoop across the canopy is no sure way to collect blooms, or fur, or wings. You cannot pick out cultural capital by sampling something else. You can't face cultural capital from behind.

The heart of the tangle: cultural capital must be associated with distinction-over; it must involve elevation and prestige and advantage. But starting with some empirical distinction-over defined in some other terms - a high level of income or education, say - cannot yield any sure grasp of what separates cultural capital from other routes to distinction. Conversely, abandoning distinction-over, in favor of analyses based on distinction-between, is to abandon Bourdieu for the quite different ideas captured by Lamont in her work on boundary-drawing.

This tangle forced Bourdieu to revise, or better, remodel his idea of cultural capital.

\section{The Vicissitudes of Cultural Capital}

An objection, raised early in the diffusion of Bourdieu's ideas, was that cultural capital might only be meaningful within a rare milieu, such as Parisian society of that era. Evidence was not long in coming that American schools did not reward familiarity with high culture or art objects in the same way, nor did cultural knowledge appear to be so crucial to social preferment in American or British contexts (Halle 1993; Lamont 1992; see Goldthorpe 2007 and Silva and Warde 2010 for British accounts).

In consumer research, Holt (1998) checked this critique of cultural capital as insular. Holt detached cultural capital from high culture and art objects. He focused not on differences in what objects were owned, but on how consumers from different social backgrounds consumed the same product categories differently. So far, so good. Holt then attributed differences, across social positions, to differences in the amount of cultural capital possessed. From that point in consumer research, high cultural capital (HCC) consumers became those people who had the tastes that Holt discovered among the people in his sample who held a high social position. In concrete terms, these were college town residents whose education and occupation, as also their fathers', fell at the high end of the sample. By this maneuver, very specific taste preferences-and anyone who spent time during the later 1990s on the gown side of the town-gown divide can guess what these were, per Lander (2008) - got anointed as markers of high cultural capital.

But I repeat: you cannot get to cultural capital by starting from a sample 
polarized in terms of social position; especially when all the sampled positions are circumscribed within a small college town in the US east of the Mississippi River. Yes, per Goffman (1951), individuals holding high social position will engage in restrictive practices; and yes, some of these practices will take the form of taste judgments applied to consumer goods; and yes, failure to internalize these taste judgments and make the correct displays will be grounds for marking out the offender as not one of us, that is, as someone holding an inferior social position. But these acts represent boundary drawing, not the deployment of cultural capital.

And yet, it is still not quite fair to categorize the use of samples polarized in social position as a mistaken view of Bourdieu, or as a misunderstanding of his ideas - because Bourdieu himself was not always true to the unique insight behind cultural capital (or, if you prefer, didn't always hew to my confection of his ideas about cultural capital). Bourdieu can be read, especially in some of his earlier accounts of cultural capital, as not saying anything different than what Goffman and Lamont say. And while Bourdieu did evolve his thinking, it was not in his interest to acknowledge that his ideas had changed. Nonetheless, to make cultural capital useful, in an online context, requires that these divagations in his thinking be untangled and pulled apart.

Bourdieu's early ideas about cultural capital were tied up with habitus, another central term in his system. Habitus consists of dispositions instilled from birth, and perfected while growing up in this kind of family occupying that social position. Habitus explains not so much different levels of cultural capital, as the word capital is conventionally used, but differences in cultural endowment. To return to my Parisian example, Alain obtains his cultural resources through his family, while Jean is sunk from the start: he was born into the wrong family. Conceived as an endowment, cultural capital does become difficult to distinguish from "to the manner born": ${ }^{3}$ a summary label for all the differences in habit and preference that flow from high versus low social position. The endowment definition implies that a woman who did not grow up surrounded by high fashionwho did not grow up wealthy, with access to haute couture, runway shows, designer brand clothing, and occasions to wear it-would lack the proper habitus to succeed as a fashion blogger. Conceived in terms of habitus, no ordinary consumer could possess or even acquire cultural capital, inasmuch as ordinary, consistent with Turner (2010), means not endowed with pre-existing social position.

To conceive cultural capital as an endowment received from the family, a habitus acquired over the years as a person matures, makes it a static notion. But to portray cultural capital as static violates the underlying metaphor: capital — economic capital — is inherently dynamic. Capital builds, disrupts, 
changes things. Per Gronow (1997), an endowment conception of cultural capital is unsustainable in the modern world, because it presumes a static social arrangement (Lamont 1992). As an endowment, cultural capital can explain reproduction (Bourdieu and Passeron 1977): how social position is maintained, newcomers denied, and upward social mobility thwarted. But static ideas like endowment can't explain modernity following the I/S/T/C Revolutions. And no static idea can explain fashion-where change is of the essence (Davis 1992).

To personify and make vivid the difference between a static and a dynamic perspective on cultural capital, compare a rentier to a capitalist. Both are wealthy, but the rentier's wealth is not active; he simply collects his rents, and spends them freely. He may not have any less wealth than the capitalist, but he is not engaged in amassing wealth through enterprise; he already has more than enough, and need not be productive. Conceived as an endowment received from birth, perfected within the bosom of the family, cultural capital reduces to habitual display. Alain displays the tastes inculcated by his family. Because the cultural rentier's family already holds a high social position, these tastes will match the tastes of others whose families also hold high positions. Shared habitual tastes cement his membership in the elite, in the time-honored way of restrictive practices everywhere. In its rentier manifestation, cultural capital is a restrictive practice that excludes parvenus even as it identifies those who do belong. It is the exercise of designated tastes as a matter of habit. If not acquired from birth, it is almost impossible to display these tastes reflexively, without effort, naturally and automatically. This makes it easy to identify parvenus by the effort seen in their struggles to display proper taste.

A capitalist, by contrast, in its root financial and economic meaning, is a dynamic individual who amasses capital, who has a trajectory, so that she ends up in a different place than she started. A capitalist invests capital to earn a return of even more capital. Her capital produces. She makes the effort. She gains.

Now you can see the problem Bourdieu faced: a habitus-based concept of cultural capital both denies the root metaphor, and implies almost perfect reproduction of pre-existing social position. An utterly static society, with zero social mobility, is the predicted result. Doubtless there have been such societies, but as Gronow (1997), following Simmel (1957 [1904]), hammers home, this is not a good description of Western Europe following the I/S/T/C Revolutions, and still less a good description of the contemporary United States (although Clark 2014 might be used to counter-argue this point). Bourdieu wished to be, and be seen as, an empirical sociologist, making this disjuncture, between static prediction and the observed dynamism of real societies in the West, a vexing problem. 
Bourdieu faced a further difficulty: his own life trajectory contradicted any static conception of cultural capital, and made a mockery of the idea that habitus was all-determinative. As Box 1.4 develops at more length, Bourdieu came from modest circumstances in the extreme southwest of France. He did not grow up speaking Parisian French at home. Yet his personal trajectory raised him to an endowed chair at the most illustrious academic institution in France. Bourdieu was the French equivalent of hillbilly goes to Harvard, or the don from Donnybrook. His trajectory is inconceivable in a truly static society where family-inculcated habitus acts as a restrictive practice to control access to high social position. Bourdieu, the scholar of global renown, was the grandson of a peasant from a marginalized rural group, among the Appalachians of France.

\section{Beyond Habitus}

In response to critiques of its static character (Schatzki 1996), Bourdieu's thinking evolved away from a reliance on the concept of habitus toward a reliance on field. He began to speak of field-specific capital (Swartz 1997). He focused less on social position within society as a whole, and more on how people maintained or advanced their position within a field. Bourdieu gradually ceased to speak of cultural capital, or of any type of capital, replacing these with either "specific capital" or "[name of field] capital" (Bourdieu 1998, 1999, 2008).

The more dynamic concept of field-specific capital emerges in this alternative account, also given in Bourdieu and Wacquant (1992):

A capital does not exist and function except in relation to a field ... We can ... compare a field to a game ... [and] picture each player having in front of her a pile of tokens ... players can play to increase or conserve their capital ... A species of capital is what is efficacious in a given field, both as a weapon and as a stake of struggle, that which allows its possessors to wield a power, an influence, and thus to exist ... instead of being considered a negligible quantity. (pp. 98-101)

Here there emerges a view of capital that could explain why some bloggers are able to grab the megaphone and acquire a mass audience. In the later Bourdieu, a consumer can put her tokens at risk to amass more. Capital can be invested and further accumulated, just as money can.

Field-specific capital can act as both input and output: "as a weapon and as a stake of struggle." This evolution rejuvenates the money metaphor that underlies references to capital. Money is distinct, relative to most resources: it can be invested to generate more of itself, with the amount of money returned a function of the risks taken. Cultural capital emerges as a resource, for cultural matters and within the aesthetic domain, which can 


\section{BOX 1.4 BIOGRAPHICAL NOTES ON BOURDIEU}

When Bourdieu's ideas began to diffuse in the Anglo-Saxon world, in the 1980s, facts about his life, of the sort found in Bourdieu (2008), were not well known among scholars. Even today, scholars outside the sociological core might find it difficult to distinguish Bourdieu from, say, a Foucault, Derrida, or Lacan. Aren't they all Parisian intellectuals, members of the French avant-garde of the 1960s? No. Bourdieu's origins differ from what the image of a Parisian intellectual suggests.

Bourdieu grew up in a remote region of southwest France speaking a scorned provincial dialect, grandson of a peasant farmer, and son of the village postman. His youthful experience of the French school system seared him. After a Dickensian boarding school experience, his scholastic ability was such, that despite more than 300 detentions, he advanced through competitive examinations to an elite École, where he received a degree in philosophy. Drafted into the army, having refused officer's training, he was sent to the Algerian front in a unit "made up of all the illiterates of Mayenne and Normandy and a few recalcitrants ... second class soldiers, illiterates from the whole of western France" (2008, pp. 38, 95). There he turned to the study of sociology and anthropology, and on his return to France, advanced to a series of professorships, and ultimately to the pinnacle of French academe, a Chair at the College de France. He never submitted his Doctoral thesis.

As mentioned, Bourdieu studied philosophy before turning to sociology. But this sentence misleads. The American reader assumes it means something like: Bourdieu majored in philosophy as an undergraduate, or perhaps, Bourdieu switched programs in grad school. Actually Bourdieu passed an entrance exam to study philosophy at the École Normale Superieur (ENS). This is an elite school, whose entrance exam Jean Paul Sartre and Michel Foucault failed on the first try, one that Jacques Derrida failed twice, and that the philosopher Gilles Deleuze never did pass (Gutting 2011). Deleuze had to go to the Sorbonne as his safety school, to use another American term. After ENS, Bourdieu got his teaching credential in philosophy (Fr. aggregation). But that's another woefully misleading statement in an American context, where teaching credential, in elite circles, does not cue positive inferences. In France, however, to obtain the aggregation required a written and oral exam, which at the time, may have exceeded in stringency the combination of the comprehensive exam and oral dissertation defense required to earn a $\mathrm{PhD}$ from an American university. It took Foucault and Derrida two tries to pass the aggregation; in Foucault's year, 94 percent of those who took the aggregation, all presumably graduates of the ENS and other Grande Écoles, who had survived the earlier culling, nonetheless failed it. This gives some perspective on "Bourdieu studied philosophy."

Bourdieu was very bright. Yet he was an outsider to the establishment, and always remained conscious of that fact. He owed everything to school but nourished a lifelong desire for revenge against the tyranny of academic categories (Swartz 1997). He could be the academic equivalent of a street brawler, a junkyard dog loosed on the genteel precincts of the Parisian salon. He was a villager in the metropolis, a peasant among lords, a scientist against the philosophes, even as he was a Humanist against the Positivists. 
be wielded as a weapon, to win a struggle for position, and also awarded as stakes, to those winning that struggle. This formula isn't found in Veblen, Goffman, Lamont, or anywhere else; it is unique to Bourdieu. This later definition redeems the root metaphor of capital. This thing called capital is not only manifest as money, as economic capital, but also occurs, and can be accumulated, in other spheres as well.

This dynamic sense of cultural capital can be linked back to taste, and taste judgments will take us forward to fashion blogging. But before making that return, there is more to be said about Bourdieusian capital, cultural and otherwise. These next few pages are offered as janitorial work, clean-up, to help the dynamic sense of cultural capital emerge more clearly from the matrix of neighboring ideas, superficially similar but unrelated ideas, and misunderstood relationships with yet other ideas.

Once the Bourdieusian idea broadens out to field-specific capital—one capital, many fields - we have to confront a new rival, the human capital of Becker (1993). To grasp the challenge posed by Becker, let me ask you a rhetorical question. If you were new to these matters, which phrasing would you select, as the more plain and lucid: field-specific capital, with its many substitutions - academic capital, educational capital, social capital, political capital, bodily capital, as many as there are fields - or just, plain, human capital?

\section{THE FORMS OF CAPITAL}

Another problem dogs attempts to apply Bourdieu's idea of cultural capital. Bourdieu didn't only refer to cultural capital, but discussed many other forms of capital as well. And his occasional attempts to corral his usage of capital, most notably Bourdieu (1986 [1983]), sometimes create as many new difficulties as they remove. I am reminded of a feature that used to run in the New Yorker magazine, called "Block that metaphor," which offered snippets of writing where the metaphors tumbled over one another, or were really a stretch. Bourdieu's writing on capital recalls that New Yorker feature. The question that emerges, from the welter of Bourdieu's usage, is whether cultural capital, and the other forms of capital found in Bourdieu's writing, is only a metaphor, and not a theoretical idea; ${ }^{4}$ that is, does not refer to a real cause. DiMaggio (1979, pp. 1468-69) put this criticism well, and notably, could offer it as early as the 1970s, when Bourdieu still had thousands of pages yet to write, and countless metaphors to unleash:

capitals proliferate: in addition to economic, cultural, and symbolic capital, we have linguistic capital, social capital, academic capital, scholastic capital, 
credentialed cultural capital, capitals of authority and consecration, university, scientific and artistic capital ... As the number of capitals increases, the metaphorical currency undergoes inflation and its value declines accordingly.

\section{Metaphor or Theory?}

To anchor this discussion, let's focus on economic capital. Many people accept economic capital as real, and not synonymous with either currency or money. Real or not, economic capital is a very intangible entity, and not easy to understand or simple to explain (for instance, try sometime, to explain money to a preteen, without defining it as currency or coin). And although capital is a real entity in economic theory, this reality, embodied in equations, is not necessarily the same reality as that of capital in the world, as seen in the daily operation of business (ideally, the two are not alien). And, the theoretical capital visible in a Keynes is not the same real thing as the capital visible in Marx, or that seen in a contemporary textbook of macroeconomics, even as the reality of any and all of these formulations remains open to scientific questioning. Note finally that the reality of capital in a textbook on microeconomics won't be the same as that of the capital discussed in a macroeconomics textbook. And it bears emphasis that economic capital, whatever it is, is not the same thing as money, wealth, or assets.

This brief excursion bodes well for the reality of cultural capital: it suggests that very difficult and subtle ideas, having an uncertain relationship to similar concepts, can nonetheless refer to real causes, as economic capital does. The question becomes, are all the forms of capital of which Bourdieu spoke real, or as real as cultural capital might well be? Any of several answers is possible. Cultural capital might enjoy a special place in the pantheon of non-economic capitals. Or, per Bourdieu's (1986 [1983]) attempted summary, there may be a master triumvirate of capitals: economic, cultural, and social. Or, per the later Bourdieu (2008), there may be only one non-economic capital, whose count of manifestations equals the number of fields where the phrase "both as a weapon and as a stake of struggle" applies.

This question cannot be resolved by reading Bourdieu, especially not in the English to which I am confined. In any case, I don't care what Bourdieu's final word was, or what he really thought. I care about what can be done with his ideas to illuminate my subject, the new things consumers do online. The test is whether my take on Bourdieu stimulates other scholars to build on this account. I acknowledge this to be a very American attitude, not so much disrespectful of authority as oblivious (Reed-Danahay 2005). It would be inappropriate, if my task were intellectual history or 
biography, where I would need to nail down the elements in Bourdieu's thinking shared with Foucault and with early French structuralists, what was new in Bourdieu versus what was repurposed from Weber, and so forth. But that is not my task.

I need to break you free of the conviction that cultural capital has a settled meaning, like a good encyclopedia entry should; or that Bourdieu's (1986 [1983]) book chapter represents a reliable summary of his mature thinking about capital; or that terms like social capital, educational capital, academic capital, and the many other usages scattered through Bourdieu's work are unproblematic instances of some basic, underlying idea of capital. Bourdieu was not a straightforward thinker. He wasn't a hedgehog, to use a contemporary metaphor, who had one big idea. Not to put it too bluntly, his work is a mess; or rather, a mash, a great yeasty mass of intellectual ferment, in the end very nutritious, even intoxicating, if you have the intellectual enzymes needed to digest it, which it is the purpose of this essay to provide.

To start, let's plant this stake in the ground: the capital metaphor is theoretically fruitful. Social settings do exist where resources can function as "both a weapon and a stake of struggle." And any such resource is aptly metaphorized by using an economic vehicle such as capital, because money is one of the very few inputs identical in form to its output. Most inputs are transformed into a dissimilar output. Food exemplifies the normal case: tasty morsels are transformed into useful heat and repellent waste. Money is different: as the saying goes, "It takes money to make money." Money itself-more money - is the output of inputting money to an investment process.

\section{How Many Capitals?}

Capital can be an apt metaphor in any social domain where performing an activity produces a greater capacity to perform it. Unfortunately, after some years of reflection, and good-faith attempts to adopt Bourdieu's (1986 [1983]) position, I have had to conclude that in most domains, to refer to this or that capital is to give only a metaphor, and to fall short of theory. Mere metaphor occurs whenever we can offer an equally good and more straightforward, if less literary, description.

A case in point is social capital, as Bourdieu (1986 [1983]) defined it: the number of social connections. The capital metaphor at first appears apt. It is easy to see how effort invested in making social connections might make these connections produce even more connections, in the same way that investing money produces even more money. If you already have many social connections, this makes it easier to gain new social connections, 
just as it is easier to make a million more dollars, if you already have half a million, than if you have only a few thousand dollars in savings. And it is the social connections themselves that produce additional social connections, just as it is money that makes money.

But, however applicable, what is gained by applying the metaphor of social capital to the count of social connections? ${ }^{5}$ Such locutions might help hitch a ride on the coattails of Economics, Queen of the Social Sciences. It might even be necessary to flog the capital metaphor, if you wrote for an audience that had a Vince Lombardi view of Marx: "capital isn't the most important thing in human affairs - it's the only thing!" Perhaps that view of Marx was widespread in Paris, when Bourdieu began his career. And Karl Marx's work continues to resonate for young Americans on the Left. The fascination, with calling everything a capital, perhaps comes from the sense of having grasped through Marx a revelation: everything comes back to money. Those not grounded in the Marxist intellectual tradition do well to recognize that calling everything a capital rests ultimately on a fascination with Marx's thought. The degree of fascination depends on how appealing you find his materialistic take on the human condition. But invocations of Marx do not a theory make, and no number of allusions to Marxist theory can turn a metaphor into a theoretical concept.

In the end, Bourdieu wanted to be a scientist, a scientific sociologist, and however powerful metaphor may be as a literary or even a teaching device, an enormous gulf separates metaphor from scientific theory (or at least, today almost every scholar in the social sciences believes this to be the case; see the Epilogue for further reflections inspired by Foucault). Social connections can be counted and measured in the normal scientific way; social capital suggests something more. The insight that social connections lead to more of the same is easily grasped. What is gained by adding a metaphorical gloss, and speaking of social capital?

Taking social capital as an exemplary case, might cultural capital also be naught but a metaphor, having an equally effective and more straightforward counterpart, one that can be readily quantified? This challenge must be confronted if Bourdieu's legacy is to bear fruit. We cannot assume that cultural capital has potential as a scientific idea, just because Bourdieu was a great thinker, or because he is a frequently cited authority, or because it's listed in encyclopedias. If we are to be scientists, then tradition counts for little; it doesn't matter that cultural capital has been accepted as an informative notion for several decades. To try another metaphor, think of Bourdieu's oeuvre as a large and elaborate vegetable garden, containing unique sub-races produced over many years of cross-breeding, unfortunately abandoned by the gardener some time ago, and now in a sorry, 
tangled state. The garden remains verdant, and still contains valuable and rare plants, but it is choked with weeds and gone to seed.

\section{Metaphor Run Amok}

As I was writing this section, the October 2014 issue of the Journal of Consumer Research (JCR) arrived, containing a paper that illuminates the consequences of not weeding the garden of Bourdieu's ideas about capital (McAlexander et al. 2014). I won't be discussing this paper's primary aim, which is to delve into the experience of leaving a major Church, Mormon in this case, under Late Capitalist conditions where everything is marketized. And I want to apologize in advance to the authors if the verbiage I criticize was added at the behest of reviewers, as sometimes occurs at this journal. Keep in mind that $J C R$ is the finest and most prestigious journal in consumer research, one that rejects 90 percent of papers submitted. McAlexander et al. had to run a gauntlet which few survive, where reviewers took whacks with a stone ax, slashed with an obsidian blade, threw mud in its authors' faces, tried to trip them up, before it could be published in the $J C R$, and come in for criticism here.

The value of quoting from the paper lies in showing what happens when all of Bourdieu's ideas about capital are accepted as is, everything harvested and put in the pot, weed and seed. The authors state:

The most important form of symbolic capital in Mormonism, indeed the distillation of all other forms of capital, is ... worthiness ... Like all symbolic capital, worthiness is interpreted, discerned, and judged by members of the field who have the cultural capital to do so ... [what others] call spiritual capital is simply symbolic capital derived from field-specific cultural capital and social capital. (McAlexander et al. 2014, p. 866)

the fear of losing field-dependent symbolic, social, and economic capital can also make leaving a field very difficult . . . field-specific symbolic capital (status) predictably loses its value outside its field of origin ... [but we found that] fieldspecific cultural capital can be migrated to an oppositional field. (ibid., p. 872)

To see the difficulty posed by this barrage of references to capital, imagine that these passages had appeared in a college admission SAT test, followed by multiple choice questions designed to measure reading comprehension. Like this:

In the passage, symbolic capital refers to:

1. Status

2. A master capital that integrates other forms of capital 
3. One of several types of field-specific capital

4. One of several types of capital present across multiple fields

5. In the religious sphere, a more apt term than spiritual capital.

It would be a very difficult SAT question, inasmuch as all the answers are supportable, but each one denies the correctness of the other. This style of thinking, which multiplies capitals without end, does Bourdieu no favors.

For instance, given the second definition from Bourdieu and Wacquant (1992) quoted earlier in this essay ("A capital does not exist and function except in relation to a field"), the term field-dependent seems redundant with field-specific: how could a resource specific to a field not depend for its efficacy on remaining within that field? And once there is field-specific capital, how can there be field-specific cultural capital, field-specific social capital, and so forth, since naming them separately, and applying them across multiple fields, requires precisely that they be field-independent types of capital? And what can it mean for your symbolic capital to be dependent on the cultural capital of others? Or to parenthesize symbolic capital, using the everyday word status? Readers not already initiated into the cult are going to get stuck on this verbiage, and find it more an obstacle to understanding than a route to it.

My point is not to criticize these authors. It's easy enough to pull quotes from the vast corpus of Bourdieu's own work to create the same jumbled impression (see Box 1.5). Here is a flagrant example from the later part of Distinction, the book that made Bourdieu's international reputation:

engineers have the monopoly of the means of symbolic appropriation of the cultural capital objectified in the form of instruments, machines and so forth ... [but] the profits accruing from their cultural capital are at least partially appropriated by those who have power over this capital, that is, those who possess the economic capital (1984, pp.301-302)

This passage cues the same critical response as the one by McAlexander et al. (2014): if cultural capital is an autonomous resource, how can economic capital dominate it? How can cultural capital be both objectified in an instrument, and possessed by a person? Why would cultural capital have first to be symbolically appropriated, when it is "efficacious in a given field," per Bourdieu and Wacquant (1992)?

No single term can stretch to include both the exercise of taste displayed in fashion blogging, and the knowledge incorporated into machinery and instruments. The elastic snaps, and the idea fails.

We must show great discipline in applying modifiers to capital, if Bourdieu's legacy is not slowly to be dismissed, as just another piece of dated obscurantism erupted out of Paris. At Bourdieu's worst and most 


\section{BOX 1.5 THE MANY CAPITALS OF BOURDIEU}

Below, I've tabled some of the different ways Bourdieu used the term capital. My purpose is not to catch out Bourdieu, but to show how loosely and metaphorically he approached the notion of non-monetary capital, in contrast to the seemingly tight definitions found in Bourdieu (1986 [1983]). Too many people think that essay wraps Bourdieusian capital into a neat package, as clear and structured as Aquinas.

\begin{tabular}{|c|c|}
\hline Quotation and source & Comments \\
\hline $\begin{array}{l}\text { "capital can present itself in three fun- } \\
\text { damental guises: as economic capital, } \\
\text { which is immediately and directly con- } \\
\text { vertible into money ... as cultural } \\
\text { capital, which is convertible, on certain } \\
\text { conditions, into economic capital ... } \\
\text { and as social capital, made up of } \\
\text { social obligations ('connections')" } \\
\text { (1986 [1983]) }\end{array}$ & $\begin{array}{l}\text { This is the conventional tripartite defi- } \\
\text { nition, adopted by those who view } \\
\text { cultural capital as straightforward. The } \\
\text { tripartite division postdates Distinction, } \\
\text { where the key graphics have only the } \\
\text { two dimensions: cultural and eco- } \\
\text { nomic capital. }\end{array}$ \\
\hline $\begin{array}{l}\text { "Cultural capital can exist in three } \\
\text { forms: in the embodied state, i.e., in } \\
\text { the form of long-lasting dispositions of } \\
\text { the mind and body; in the objectified } \\
\text { state, in the form of cultural goods ... } \\
\text { and in the institutionalized state ... in } \\
\text { the case of educational qualifications" } \\
\text { (1986 [1983], p. 47) }\end{array}$ & $\begin{array}{l}\text { The definition of embodied cultural } \\
\text { capital in terms of dispositions sets up } \\
\text { a confusion with habitus. To speak of } \\
\text { educational qualifications raises the } \\
\text { question of how Bourdieu's cultural } \\
\text { capital differs, if at all, from Becker's } \\
\text { human capital. }\end{array}$ \\
\hline $\begin{array}{l}\text { "cultural capital, which we should in } \\
\text { fact call informational capital to give } \\
\text { the notion its full generality" (BW 1992, } \\
\text { p. 119) }\end{array}$ & $\begin{array}{l}\text { If cultural capital is information, } \\
\text { how does it differ from knowledge, } \\
\text { i.e., the human capital of Becker? }\end{array}$ \\
\hline $\begin{array}{l}\text { "capital presents itself under three } \\
\text { fundamental species ... to these we } \\
\text { must add symbolic capital, which is the } \\
\text { form that one or another of these } \\
\text { species takes when it is grasped } \\
\text { through categories of perception that } \\
\text { recognize its specific logic" (BW 1992, } \\
\text { p.119) }\end{array}$ & $\begin{array}{l}\text { How can cultural capital be defined } \\
\text { apart from the symbolic realm? In } \\
\text { some later work, symbolic capital } \\
\text { tends to supplant the others, suggest- } \\
\text { ing again a generalized metaphor of } \\
\text { (non-monetary) capital. But for these } \\
\text { purposes, Bourdieu ultimately settled } \\
\text { on "specific capital." }\end{array}$ \\
\hline $\begin{array}{l}\text { "symbolic capital, commonly called } \\
\text { prestige, reputation, fame ... is the } \\
\text { form assumed by these different kinds } \\
\text { of capital when they are perceived and } \\
\text { recognized as legitimate" (1991, } \\
\text { p.230) }\end{array}$ & $\begin{array}{l}\text { Here Bourdieu appears to conflate the } \\
\text { outcome of the capitals-distinction- } \\
\text { with another species of capital. }\end{array}$ \\
\hline
\end{tabular}




\begin{tabular}{|c|c|}
\hline Quotation and source & Comments \\
\hline $\begin{array}{l}\text { "The state [concentrates] different } \\
\text { species of capital: capital of physical } \\
\text { force or instruments of coercion (army, } \\
\text { police), economic capital, cultural (or } \\
\text { better) informational capital, and sym- } \\
\text { bolic capital ... [leading to] the emer- } \\
\text { gence of a specific, properly statist } \\
\text { capital ... [and] the concentration of } \\
\text { juridical capital, an objectified and cod- } \\
\text { ified form of symbolic capital" (1998, } \\
\text { pp. } 41,47 \text { ) }\end{array}$ & $\begin{array}{l}\text { Note the disappearance of social } \\
\text { capital. To call the army a capital } \\
\text { shows how far Bourdieu was willing to } \\
\text { stretch the metaphor. This essay, } \\
\text { which postdates "The Forms of } \\
\text { Capital" by a decade, makes it difficult } \\
\text { to maintain that Bourdieu defined } \\
\text { exactly three types of capital, neatly } \\
\text { separated and organized in accord- } \\
\text { ance with the first quote. }\end{array}$ \\
\hline $\begin{array}{l}\text { "have to be able to consider the society } \\
\text { activities of the aristocrat, or the reli- } \\
\text { gious activities of the priest or rabbi, as } \\
\ldots \text { oriented towards preserving or } \\
\text { increasing specific forms of capital" } \\
(1990, \text { p. } 88)\end{array}$ & $\begin{array}{l}\text { Aristocratic capital? Rabbinical } \\
\text { capital? Is there no limit on how far the } \\
\text { metaphor can stretch? }\end{array}$ \\
\hline $\begin{array}{l}\text { "science ... must endeavor to grasp } \\
\text { capital and profit in all their forms and } \\
\text { to establish the laws whereby the dif- } \\
\text { ferent types of capital (or power, which } \\
\text { amounts to the same thing)..." (1986 } \\
\text { [1983], p. 47) }\end{array}$ & $\begin{array}{l}\text { Power and capital can only be the } \\
\text { same thing in a loose metaphorical } \\
\text { usage of each. }\end{array}$ \\
\hline
\end{tabular}

Note: The year given links to the quotation to citations in the references section. If there are no initials, the citation is to a sole-authored work by Bourdieu; initials indicate a co-authored article, i.e., BW for Bourdieu and Wacquant (1992).

ineffective, references to capital become a tic, a label to be slapped on just about any trait, resource, or item of value, many of which already have a good everyday referent (for example, bodily capital in place of good looks, or educational capital for education). Absent an urge to draw the mantle of Marx around oneself, and to enforce a reading of social being in terms of "it's all about money," this reflexive labeling of everything, as some type of capital, is pointless, and cannot help us to explain social reality.

If cultural capital is not taken as unique, then either there is one type of non-economic capital, a core metaphor of money manifest across all fields; or, there are many types of capital, which each have to be justified and carefully distinguished, and not said to be both field-specific and manifest across fields. Under the first branch we can accept, as a handy abbreviation, when the underlying money metaphor is applied within a field, references to academic capital, spiritual capital, political capital 
and any other name-of-field capital; but our usage must be strict, and be limited to academic capital and no other, when we are working within the academic field. That way we preserve the fruitfulness of the underlying money metaphor, while harvesting that metaphor in a wide variety of fields. But as soon as we slip, and refer to the social capital gained in academia, by having a degree from an elite university, or the cultural capital obtained in academia, from publishing in top journals, while elsewhere reverting to academic capital, then Babel ensues.

I do not believe there can be many types of non-economic capital. Money isn't everything, everywhere. The metaphor isn't that fruitful. And there's no stopping rule, which is why Bourdieu continued to proliferate references to fill-in-the-blank capital for decades after declaring in Bourdieu (1986 [1983]) that there are but three (Box 1.5). And to introduce symbolic capital as "one ring to rule them all," while tying it back to the old term status, scrapes the nail across the chalkboard. Bourdieu's beautiful idea, grown over-ripe, rots into jargon.

\section{Another Rival: Human Capital}

Unfortunately, when we try to protect Bourdieu, by abstaining from needlessly proliferating forms of capital, we open him up to a new avenue of attack. If there is only one underlying capital metaphor, that likens resources across many fields to money, why not refer, as the economists do (Becker 1993), to human capital? It's a simpler term than field-specific capital, and the reference to human, because it is so encompassing, doesn't feed the temptation to proliferate labels across fields. In English, we refer to human when we want to invoke universality, some property or capacity, shared by all, across every human context - every field. One underlying metaphor yields one overt label. And who better to apply an everythingis-money metaphor than economists, who know the most about the real vehicle for the capital metaphor? Bourdieu was alert to the danger posed by rational choice economics, and the risk of having his metaphor hijacked. He repeatedly inveighed against Becker (see Box 1.3).

You may never have seen my gambit here before. To challenge the utility and legitimacy of Bourdieu's thinking, by substituting human capital for the unending mentions of fill-in-the-blank capital-it just isn't done in polite company. An Us-versus-Them mindset has developed among those favorably inclined toward Bourdieu's work. ${ }^{6}$ Not many English-speaking business academics read Bourdieu, and nobody finds him an easy read. If one has invested-I was about to say intellectual capital, but trust you can see its redundancy, courtesy of this aside - in grappling with Bourdieu, he becomes the home team and the underdog. Mainstream economists like 
Becker and psychologists like Kahneman dominate English-speaking business academia; the sociologically inclined and invested are a marginalized minority. No one so inclined wants to be relegated to the periphery of the all-conquering Economics discipline. Besides, if you have an overarching personal commitment to the political Left, as sociologists often do, Becker and the other rational choice economists can never be forgiven for their dismissal of Marx. Human capital comes out of the wrong economics tradition.

But the challenge posed by human capital, as an alternative formulation of what Bourdieu came to call field-specific capital, will not go away. In most applications, human capital refers to skills and knowledge. Interestingly, skills and knowledge are input factors akin to money, inasmuch as the input looks very like the output. Practicing a skill yields more skill. The more you know, the more you can know. Human capital is also attractive ideologically: it substitutes for the Marxian maxim, "it all comes down to money," a replacement of the form, "it all comes back to learning." Knowledge is wealth. Knowledge is the master resource. And if it is true that we now live in a knowledge economy, with the diffusion of the Web a case in point, then human capital might yield a more fruitful metaphor, relative to any Marx-derived metaphor dating to the metal-bending manufacturing age.

Ideas about human capital have shortcomings. Any reference to the panhuman denies group differences (Box 1.6), and carries ideological water for one philosophy of science versus others, privileging psychology and biology over sociology and anthropology. But human capital has to be taken seriously as a well-founded rival, most threatening when the fieldspecific capital formulation is adopted and flogged (one capital, under heaven, manifest in many fields, hallowed be thy name). Human capital would not so threaten, if Bourdieu had been able to confine himself to one or a few types of non-economic capital; but he never had that discipline, or not for very long.

\section{What Is Cultural Capital?}

The chain of reasoning thus far: (1) Cultural capital doesn't have a settled meaning, not even in Bourdieu's own work. (2) Some interpretations of cultural capital blur it with other sociological notions, such as the restrictive practices of Goffman or the boundary drawing of Lamont, so that whatever innovation Bourdieu made is lost. (3) Sampling across polarized social positions and attributing differences to the presence of cultural capital is a dead end. (4) Some readings of cultural capital can only apply to a highly static society with little mobility, and hence, are not 


\section{BOX 1.6 NATURAL HUMAN}

An acquaintance with sociology, or anthropology, produces a deep-set skepticism toward claims of the kind, "It is human nature to ...." For a sociologist, the baseline is never the human, but rather, "People in this social group characteristically ...," while for anthropologists, the baseline is "Members of this culture are wont to ...."

For sociologists and anthropologists, the epistemic value of labeling an action as human, universal across all groups, now and forever, is inherently suspect. Not much in the social, cultural, or political spheres is universal. Hunter gatherers differ from peasants, who differ from city dwellers, who differ again from Late Capitalist consumers. They are all Homo sapiens, and that's important, for understanding the shared physiology that unites us. But the sociologist must resist the notion that our social being is a fixed concomitant of our biology, no less universal than the ability to convert sugars into cell energy. No. There are countless differences across groups.

In a sociological frame, to claim that something is human nature is to make a rhetorical move, to sneak in a claim that some viewpoint is uncontestable, correct beyond any questioning, because it is natural, as plain as the nose on your face. Or it is a reductive move, an assertion that the differences across collectivities and cultures are superficial, in comparison to the shared biological substrate, which actually drives behavior.

The sociologist believes in difference, in variation at a fundamental level, over groups and across time, within his proper sphere of the social and collective. If you want to be a consumer sociologist, you must learn to highlight every mention of human nature, in any text you read; to stop in your tracks, pause, and reflect: "Wait a minute; what claim has been slipped in here, and on what grounds?" Else, you may succumb to biologism.

useful to describe a modern consumer society, and especially not fashion categories within it. (4) The meaning of cultural capital must tie back to the underlying metaphor of money. (5) Unfortunately, this metaphor runs riot in Bourdieu's work and in many of those who claim him as a source. (6) Run riot, the metaphor risks losing its potency, and becoming mere metaphor, a literary embellishment of ideas that could be expressed in more familiar, straightforward and illuminating ways, which would be more productive from a scientific standpoint. (7) A defensible solution to the problem of proliferating capitals is to speak strictly of field-specific capital, a capital that always ties back directly to the money metaphor, expressed differently as needed to accommodate each field. (8) However, a single underlying non-economic capital, independent of field, might more simply be labeled human capital, tying the root metaphor to skill or knowledge, and returning ownership of the metaphor to non-Marxist economists. (9) Leaving Bourdieu and sociology with nothing. 
The most fruitful path forward is to retain the idea of cultural capital, but ditch the other capitals: social, symbolic, field-specific, fill-in-the-blank capitals, every one. In terms of intellectual history, this is to acknowledge Bourdieu for a great insight, which got diluted through overgeneralization, into the coils of which later authors have become entangled, to the exclusion of the genuine insight with which Bourdieu started, and to which he often returned, without ever having the discipline to stick with it. Cultural capital, flexibly interpreted across the fields to which it pertains - which are far fewer than all fields - can be defended as not mere metaphor, and as not the same thing as restrictive practice, and as more illuminating than other contending ideas, such as human capital. Cultural capital is real, with a theory behind it; all other references to non-economic capital may be dismissed as metaphor, confusion, or ideology.

In sum, to understand fashion blogs, we first had to preserve and replenish the insight underlying cultural capital, by pruning back the overgrowth and tearing out the weeds. Stripped back to its essentials: (1) A few people possess a wealth that is not money wealth. (2) Some people, whom we might call cultural capitalists, can amass this non-financial wealth, and even reinvest, to earn more. (3) This investing and accumulating only occurs in the domain of cultural goods. (4) Some but not all consumer goods are shaped by what Bourdieu called "the cultural arbitrary." (5) Therefore, some consumers, of some types of goods, can amass and deploy cultural capital.

\section{TASTE AND CULTURAL CAPITAL}

To accomplish this pruning, so that Bourdieu's ideas may once again bear fruit, the discussion of cultural capital has to be recentered on the idea of taste. At first glance, this may not seem to help much. The term taste is subject to as many conflicting definitions as cultural capital. Explaining the one in terms of the other is like having to solve a single equation with two unknowns. But cultural capital can't be rescued from rivals, such as human capital or restrictive practices, and made useful for studying consumers online, without linking it to taste. We gamble that taste and cultural capital participate in enough sentences, in enough different contexts, to not leave us with two unknowns in a single equation. Rather, we gain two places from which to view our subject, which is the megaphone effect manifest in fashion blogging, seen now in stereo vision. 


\section{What Is Taste?}

Taste is contested (Gans 1999; Gronow 1997; Holt 1998; Johnston and Baumann 2010; Lynes 1980 [1955]). As Bayley (1991, p. xviii) puts it, "an academic history of taste is not so much difficult as impossible." The meaning of taste in the West has been controversial since at least the 18th century (Gronow 1997). A fact that complicates discussion, and promotes confusion: taste is owned by at least three, and possibly four or five disciplines, each of which claims, as Bourdieu was wont to say when in a Weberian mood, a monopoly on the legitimate use of taste. It will clarify matters if I first name these disciplines and state their claims on taste.

The oldest claim belongs to the field of aesthetics, as when critics evaluate individual works of art, music, and literature. Here taste is the capacity that enables a person to act as a literary or art critic. Good taste in literature means the ability to discriminate the sentimental from the sublime, the schlock from the genuine, the merely pretty from the truly beautiful. Taste in an artistic context has elements of a habitus. The very tasteful critic is unable to enjoy pulp or kitsch - mere exposure makes him retch-but responds readily to the great or sublime, at which he swoons. The dullard who lacks taste simply cannot enjoy a Proust or a Joyce, a Stravinsky or a Schoenberg, a Duchamp or a Pollock; the capacity to appreciate the art in these more challenging works is missing. The clod has not got the habitus to see the art.

The critic appreciates true art, and beauty provides one of several anchors for existence, once God is Dead. Within an artistic context, to possess good taste signals character and establishes worth. Bad taste comes from bad character, and lack of taste shows lack of worth. The elision from aesthetics to ethics is quick and easy, causing ethicists also to dispute about taste, as Campbell (1987) notes. Taste balloons out from art to encompass conduct, as in the phrase "[not] in good taste." With this elision from Beauty to the Good, the stage is set for the conflation of sociological and artistic claims on taste, as described next.

Not as old, but in the 20th century rivaling aesthetic claims for prominence, is the claim laid by sociology on taste, advanced by Bourdieu, Goffman, and others. Classically, sociologists study the connections between taste and the elite, or taste and social class more broadly. Goffman's (1951) notion of restrictive practices captures this meaning of taste. Sociologists look at taste as a class marker and as a device for policing the boundaries that fence off and protect the higher strata. Here terms of art include parvenu, nouveau, and arriviste, ${ }^{7}$ or snob, sophisticate, and swell, versus boor, rube, and hick. Good taste and bad taste line up with high versus low, subtle versus coarse, and refined versus vulgar. When in 
the grip of a structuralist fantasy, Bourdieu would natter on about such homologies.

But confusion spreads, once literary and artistic meanings of taste get mixed up with class. Bourdieu rose to prominence because he had a keen eye for class masquerading as taste, and loved to expose the pretensions of professed aesthetes, who only acted as jealous guardians of class interests. Unfortunately, some confusion of (artistic) taste with social class is almost inevitable in European societies and their descendants such as the United States. For centuries, European art that entered the canon of the great was first produced for, and primarily consumed by, a small group of the aristocratic elite. When that aristocracy ebbed, as it did at different rates in different nations in the 19th century, matters of taste became confused. Sometimes this cropped up in disputes about the quality of art in this work versus another, and sometimes in arguments about who could claim to be elite, based on what art they liked. You have probably encountered discussions of taste that did not recognize the separate claims of aesthetics and sociology, or the great danger of conflating the two.

I hope to inoculate you, so that when the term taste is encountered in neutral territory, such as a book review or newspaper article, you will immediately grow vigilant, and hesitant. Literary types know little of sociology; social scientists are too often ignorant of aesthetics and its philosophical heritage, including the link to ethics. Taste is a dangerous term; be careful out there. What masquerades as a simple metric for development of character, or fitness for elevated position, can often be unmasked as a restrictive practice, designed to defend and exclude, group identity burlesqued as good judgment and refinement.

The third claim to ownership of taste comes from ethnography, which sometimes makes its academic home in sociology departments, but more commonly in anthropology departments. Lamont's (1992) ideas about symbolic boundary drawing reflect the meaning of taste within contemporary ethnography. Ethnography comes into it because taste as boundary is taste as (group) identity, and from this scholarly apercu group identity means culture. Tastes identify a person as a member of this or that subculture, this or that voluntary association, and often, this or that marginalized, ostracized, and scorned group (Arsel and Thompson 2011; Holt 1998; Thornton 1996).

Under an ethnographic take on taste, there can no longer be good or bad taste in the literary, artistic, or ethical sense. Goffman's (1951) idea of restrictive practices becomes less apropos here. These practices restrict entry to the small elite at the apex of society, which others clamor to enter, and who emerge thereby as the right people, who presumably have the right taste, that is, good taste. ${ }^{8}$ Ethnographers tend to be radical levelers, 
scornful of the idea of an upper class, and protective of The People (best said out loud in a deep, gruff, male voice). Ethnographically, in a postBoaz world, there cannot be good taste or better taste; there are only in-group and out-group tastes. Accordingly, the role of (taste) boundaries is to include as much as to restrict or exclude. Shared tastes bring us together and make our common interests, our community, visible and real to each and all. The emphasis in ethnography is on taste practices, viewed as socially visible choices and preferences that confirm membership and confer identity.

The ethnographic take on taste has dominated discussions in my home field of consumer research, as part of work in consumer culture theory (Arnould and Thompson 2005). Works by Arsel and Bean (2013), Arsel and Thompson (2011), Holt (1998), and Thornton (1996) emphasize non-hierarchical taste preferences as the foundation of taste communities. Participants in Arsel and Thompson (2011) used taste preferences to protect their identity investments in the alternative music field, when under a devaluing assault from a commercialized mythology of the hipster. These consumers strove to know the right music to like, and the more centrally placed did tend to like the right music, the music that the most authentic among their fellows liked. Thornton (1996) similarly sees subcultural capital as a resource for authentication, which young club-goers achieve by differentiating their taste preferences from those of a despised (and fictive) mainstream. For these authors, tastes serve as a resource for drawing identity boundaries that include desired people and objects and exclude scorned others (Lamont 1992). Under an ethnographic lens, there can be no good or bad taste, but only my taste, which I discover is our taste, which shows that we belong together, and are different from them, who have no taste, because they do not share our tastes, which is how I learn they do not belong.

The ethnographic view on taste is sometimes undergirded by an explicit ideology: that there is no social hierarchy, that no one is elevated above anyone else, and hence no one can have better taste than anyone else. There are only different tastes, corresponding to different (group) identities, which group members, of course, put on a pedestal as the right taste. Here all claims to better taste are only assertions of identity, the claims of group members and wannabes. The underlying ideology may be explicit or implicit; where explicit, it may be glossed as postmodernism, the idea that during the baseline period, by about the 1990s, society had fragmented, causing hierarchy to lapse and putting legitimacy up for grabs, so that tribal identities, new and old, become the only refuge (Firat and Dholakia 2006). ${ }^{9}$

Young scholars need to recognize that there is a well-developed point of 
view, more common among ethnographically educated scholars than elsewhere, which denies the idea that there can be levels of taste. Since levels of taste are central to my analysis, I mean to alert you to these differences in ideology. For some scholars, to speak of levels of taste is bad politics, which is to say, bad taste, the taste of a foreign ideology. As a younger scholar you will need to take a stance on this matter.

A fourth claim to ownership of the term taste comes from scholarsI lack a handy label — who study food perceptions and customs (call it gastronomy? home economics? perceptual psychology?). These are scholars who study taste in the most literal and concrete sense of the term, the taste of bringing food into the mouth and onto the tongue. Gronow (1997) has an historically informed discussion, and Warde (1997), Fantasia (2010), Johnston and Baumann (2010), Gopnik (2012), and McQuaid (2015) also provide entry points. If tasting food is the metaphorical root, per Lakoff and Johnson (2008), of all usages of taste beyond eating food, then grasping literal taste, taste for food, and the extent to which even literal taste is culturally shaped, rather than natural or necessary or automatic, may repay the effort.

A consumer sociology, which does not yet exist, might someday assert a fifth claim over the meaning of taste. This claim would bear two distinguishing marks. First, it would confine itself to taste in the context of consumer goods, narrowly defined as items bought or sold in a mass market. That definition excludes art, music and literature, as outside the consumer sociologist's area of expertise. Yes, you can buy a copy of Ulysses on Amazon, but that purchase is peripheral to the experience of this work of literature, and to its cultural import, and also unnecessary, since you could check it out of a library. And most people's experience of Rembrandt does not come about through a purchase, again dismissing as peripheral the need to sometimes pay admission to a museum. Conversely, you can't check a crème brulee out of a library; either it or its ingredients must be purchased, and to experience it is literally to consume it. Neither can you get a couch from a concert hall, or take a skirt out of an art museum; it or its components must be purchased. A consumer sociology will study taste in purchased items, consumer goods for short: items mostly experienced via purchase and use, and that get used up in that experiencing, as seen most clearly with food, and so very differently in works of literature and art, which are not used up, no matter how often experienced, or by how many.

A consumer sociology has nothing to say about literature or art. It will not try to wrest the topic of taste away from literary critics. It will warily but avidly observe discussions of taste in other disciplines, with an eye to what might be learned, in humble recognition that the boundaries drawn 
around consumer sociology are imprecise. Artworks may be consumed, I suppose; this usage doesn't do violence to the ear in the way that the consumption of spirituality does. But consumer sociologists don't have the training to contribute to aesthetic philosophy, and will know better than to try.

Pop culture provides a liminal case. Pop culture can be defined as purchased entertainment. Music, film, and fiction account for the bulk. Taste is huge in popular culture. But I think it is the ethnographer who owns the concept of taste in these domains. Ethnography is primary because taste in popular culture revolves around affiliation and identity: in-group and out-group taste. The dominance of ethnography may be strongest in popular music (Arsel and Thompson 2011). For instance, I have a profound distaste for country music - how about you? But reggae, that's got a nice beach vibe. Quick: how many inferences can you draw about my group identities, and my personal history, from these two statements? If such inferences flowed readily, I rest my case, as to why taste in popular culture belongs to ethnography.

\section{Taste Goods}

The second element that marks out a consumer sociology of taste is its rigorous restriction, within the category of consumer goods, as to where taste pertains. Preferences are everywhere across consumer goods, but preference is not a synonym for taste. There are some product categories where it is meaningful to speak of taste, and many, many other categories where neither taste nor cultural capital apply.

To be concrete, food, clothing, and home furnishings are taste domains. There may be others, but interestingly, these three crop up as a triplet in Bourdieu (1984, p. 78). He groups such products under the heading of the cultural arbitrary. What might he mean by that evocative phrase? I will apply it to goods whose quality, in the usage of economists, is difficult to inspect or verify, but where people often have a visceral response, pro or con. This green couch looks putrid. A torte in this style melts in the mouth. That skirt on her makes me retch. Why call it the cultural arbitrary? Because the visceral responses, of different people, may starkly differ, and even be opposed - that sea green couch relaxes my eye. Although arbitrary, these visceral responses do cluster by group and by era; they are not purely idiosyncratic. Their shared character justifies the cultural half of the label. And yet, what makes taste responses visceral is the shock of recognitionthis is my style, this is what I like. And this gut reaction is underwritten by a tacit conviction of universality: I only like good style, stylish goods.

Later, in the Pinterest essay (Essay Three), I will try to interrelate style, 
fashion, and taste in a more systematic way. The reader who needs that clarification now can flip ahead to pages 187-224. Here the focus must stay on identifying product categories where the terms taste, style, and fashion are apropos, which are categories where the cultural arbitrary is manifest.

By this criterion, paper towels and other everyday convenience items are not domains of taste, whether toothpaste for the teeth, detergent for the clothes, or mops for the floor. These are too minor to have much aesthetic potential, or to be culturally appropriated. ${ }^{10}$ Vacuum cleaners, microwaves, desktop computers, and other machines are domains of knowledge, where consumers may differ in expertise, but not in taste. We can meaningfully say, "she has good taste in clothes," "he has good taste in restaurants," and "her apartment is tastefully decorated." But it is conceptually and linguistically awkward to say, "she has good taste in vacuums," "he has good taste in microwaves," or "her Windows file directory has been tastefully arranged." 11 These sentences contain category errors, in Gilbert Ryle's memorable phrase. We can speak of a preference for stainless steel appliances, or a liking for some brand of paper towels, or expertise in the case of computers, and we can also speak of good design in the case of a machine. But none of these requires or even allows use of the word taste, nor do we gain insight by substituting taste for preference or liking. Taste is different.

Based on these limits, cultural capital in a consumer goods context is most likely to be visible in the food, clothing, and home décor categories. Here, better is arbitrarily determined, but judgments of better are made, and shared, and felt as much as known. Here the concrete and literal meaning of taste, for food, provides a helpful anchor. If you don't like the taste of beets, you want to spit them out. Food that tastes bad, undeniably tastes bad; food that tastes good is immediately pleasurable. These are visceral not cognitive responses.

\section{Two Meanings of Taste}

To pull together the threads, consider the graph in Figure 1.1, which distinguishes a vertical from a horizontal operation of taste. In its horizontal operation taste distinguishes in from out, us versus them. The horizontal dimension captures the ethnographic take on taste. In its vertical operation, taste distinguishes better from worse, above from below, up versus down. This is the literary or artistic take. With one further assumption, it is also the classic sociological take on taste: that better artistic taste will be found to be the taste of the better sort of people; moreover, that people born to higher social positions readily like and respond to better art, in a manner difficult for people who are not to the manor born. As Bourdieu liked to say, the societal realm and the realm of art are homologous: similar 


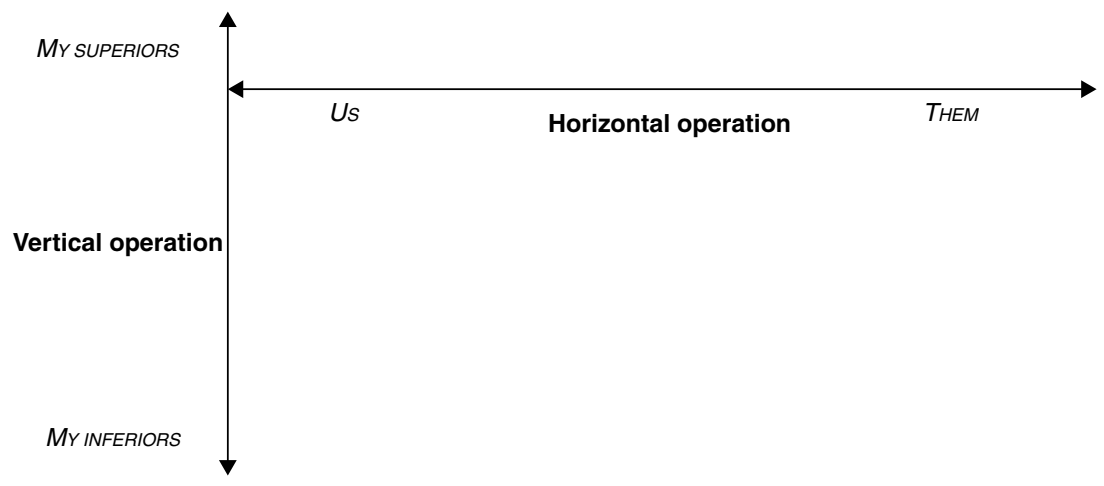

Figure 1.1 Two dimensions of taste

in structure. To which, those of us not bewitched by the structuralist fantasies of 1960s France can only respond: "Maybe." Whether truly homologous or accidentally similar, it is the shared use of taste in the vertical sense, by students of art and students of sociology, which promotes a fatal confusion of the two domains, and gives traction, especially here in America, to the ethnographic dismissal that it's all a crock; there is no better and we have no betters.

The next step, in founding a consumer sociology of taste, and retrieving cultural capital for use in the consumer sphere, is to retain the vertical operation of taste, inherited from the aesthetic realm, while leaving behind the automatic equation of better taste to endowment with better social position. Gronow (1997) provides the lock release. In the aesthetic realm, he speaks of judgment power. This is the power to discriminate better from worse in realms where there is no mechanical or standardized test; aesthetic realms, the domain of the cultural arbitrary. Better, in this domain, means more pleasing, to more of those people, who have more capacity, to take more pleasure, within the aesthetic realm at hand - net, net, net, net. Pleasure is central to this definition of aesthetic (Campbell 1987). It need not be central to other definitions of aesthetic, but again, we are focused on a few categories of discretionary consumer goods, items which provide pleasure, not the satisfaction of needs.

Aesthetic realms in the consumption sphere-domains of the cultural arbitrary - can be concisely defined as places where Consumer Reports magazine dare not go. A paper towel or a vacuum cleaner is an excellent candidate for a Consumer Reports article, which is why we can exclude these product categories from the domain of taste. The absorbency of the paper towel can be measured. The dirt removal capacity of the 
vacuum cleaner can be tested in a variety of standardized settings. Either it picks up $>80$ percent of 2 grams of dog fur dropped from a height of 50 centimeters onto a 2 centimeter deep carpet pile, or it fails. There are better and worse products in these categories, but there is not better or worse consumer taste.

Now imagine a Consumer Reports article on fashion handbags. Imagine measurements of the amount of weight that can be carried before the strap tears, of the stitch count and the regularity of their spacing, of the thickness of the leather and its grade. It would all be beside the point. None of it would help the consumer decide whether the Michael Kors handbag, with these boots and this hat and scarf, would make a pleasing impression on the people who care about looking good, that she cares about. That fashion decision requires taste.

Taste is not skill. Taste is not knowledge, and this is how we can protect cultural capital from the charge of being just another form of human capital - which has to rest on knowledge. You can have knowledge of vacuum cleaners, and skill in cleaning a house with a knack for keeping it neat. But there is no knowledge of how to appear fashionable, no facts about what will look good together, and nice on me. There is no skill in handbag selection, but you can display better or worse taste in choosing a handbag to complement an outfit. ${ }^{12}$

Aesthetic realms in consumption, domains of the cultural arbitrary, are product categories where moderately shared judgments can be made about better or worse, and where better means more pleasing to more people who get pleasure from these products. Because discriminating judgments are made, and by individuals, we can speak of taste as an individual capacity, that may be possessed to a greater or less degree. Because the pleasure is the pleasure of other people, and these other people are uncounted but potentially very many, taste isn't entirely idiosyncratic and subjective, even though it can't be said to be objective either, as developed in the Consumer Reports example. ${ }^{13}$ Because taste is not entirely subjective, it depends crucially on other people; not so much on certain individuals, but on all of us collectively, or some group of us. That is why consumer taste belongs to sociology.

Your taste has to be ratified by other people before it can be called good taste or better taste. These people can't only be part of your group, or limited to fellow travelers in your subculture; that would toss us back into the lap of ethnography, and its perspective on taste as shared ingroup preferences. Consumer taste is ratified in the mass among strangers. Because it is ratified in the mass, it will tend to be mainstream taste. Studies of taste in consumer ethnography, which focus on marginalized or oppositional groups and subcultures (Arsel and Thompson 2012; Thornton 
1996), must be set aside, not as wrong, but as unhelpful. Sociology studies strangers in the mass.

\section{Consumer Taste Levels}

The conclusion: in domains such as food, clothing, and home décor, consumers will be distributed throughout a range of taste capacity, with some consumers having little taste, most having some taste, and a few having high levels of taste capacity. It does not matter whether taste has exactly a normal distribution, but it does seem likely to be humped in the middle, with many consumers ranking neither high nor low. Next, it may be helpful to profile consumers at low, middle and high levels on the taste gradient for clothing, to show how better and worse consumer taste operates in that category. My argument does not require there be bad consumer taste (Box 1.7), only better and worse taste; a gradient from less to more.

A consumer low on the taste gradient for clothing need not make mistakes. We need not imagine these individuals dressed, Rodney Dangerfield style, in striped top with plaid bottom and polka dot coat. Rather, the consumer low on the taste gradient doesn't pay much attention to his own or others' dress (the male pronoun slipped in there). He may observe a few simple rules to avoid clashing colors and patterns. The clothing he buys is ordinary, probably neither expensive nor rare, and not much time is spent shopping. If female, accessories may be minimal, and little time will be spent in the morning deciding how to dress that day; if male, what to wear that day is only a matter of rotating through his stock. No one notices how this person is dressed; compliments are only rarely received, but also, are neither sought nor expected.

The consumer low in taste for clothes might seem also to lack what consumer psychologists call involvement with the product category. Dressing right is not important to the persons just described. And it's true: at low levels, taste lines up with involvement. No news. To grasp how taste differs from involvement, we have to move up to the middle of the taste gradient, and beyond. People with middling good taste will spend more money on clothes, and more time and effort on shopping and on dressing for an occasion. Wardrobes expand and broaden in range. Involvement is much greater. But taste will remain middling, to the extent that the following descriptions apply: (1) Not many compliments on dress are received, and these tend to be lukewarm or casual, and come mostly from people who are not themselves exemplary dressers, but who have personal or professional reasons to curry favor. (2) No one turns their head on the street when this person walks by (throughout these taste gradient examples, I hold constant a moderate personal attractiveness, by the local standard, 


\section{BOX 1.7 BIPOLAR AND UNIPOLAR CONCEPTS}

Elsewhere in the social sciences, in the design of measurement scales and questionnaires, researchers have to stay alert to the difference between bipolar and unipolar responses. A familiar bipolar case is the survey item whose five response options range from "strongly agree" to "strongly disagree." These polar response categories work well, when you study statements of opinion, where there is no right or wrong. An example: "Nuclear power is a clean form of energy." It may be low in carbon omissions, but it is not low in radiation production, so is it clean? That is a matter of opinion, which hinges on whatever clean, in the context of energy, means to the respondent.

Now consider this very different statement, found perhaps on a student evaluation form: "The instructor is highly qualified to teach this course." You can apply an agree-disagree scale to such a question, but it is a force-fit. If a respondent disagrees, is it because she perceives the instructor to be only moderately qualified rather than highly qualified, or because the instructor is perceived as unqualified? Either could be the case. And what does it mean to strongly disagree with this statement? Does it mean you are highly confident that the instructor's qualifications are exactly moderate, not high?

Personal characteristics are often distributed on a gradient from absent to present, from zero to a lesser or greater degree. There is neither minus nor plus sign, just less versus more. That's my stance on consumer taste: best to approach it as a capacity that varies from mostly absent, to minimally present, to moderately present, to present to a high degree. This maneuver helps to avoid the trap of talking about bad taste, which so often drives off an ideological substrate, rooted in group identity or social position. To speak of the relative absence of taste, rather than bad taste, keeps discussion on a neutral plane.

Speaking to the PhD student: beware of bipolar concepts. Left brain versus right brain thinking is a familiar and pernicious example. Bipolar concepts tend to become all-embracing, and hence, empty. Bipolar concepts are magnetically attracted to one another; everything lines up: heaven and earth, male and female, yada yada. A silly and hollow structuralism threatens. Unipolar concepts cry out for supplements. Unipolar concepts never quite line up, preserving a rich diversity of intellectual content that has some hope of capturing the real.

when naked, unadorned, and without cosmetics). (3) This person does not believe herself to have excellent taste, and doesn't strive to make her clothing choices exemplary or outstanding. She's careful about how she dresses - she's involved - and would be appalled to be thought badly dressed. Dressing is important, but she's not greatly accomplished at it, or invested in becoming more accomplished.

At the high end of the taste gradient, involvement in the product category may not be any greater, nor need the expenditure of money, time and effort; but a different set of descriptors applies: (1) This person often gets compliments, these compliments are sometimes enthusiastic, and 
compliments come from a broad spectrum, not just people with strong ties or a need to curry favor. (2) Compliments come from people who themselves receive compliments on their dress. (2) People who don't know this person do turn their head to take a second look, when she walks by; and the glance of every one tends to linger, once she's been noticed, which she is more likely to be, than others in the room. (3) She's confident about her dress. Deciding what to wear in the morning, and having to decide what to wear for a novel occasion, are positive challenges, exciting and engaging. She'll take a risk in her dress, when in the mood, and wins that wager more often than not. She's got good taste in clothes.

I hope it has dawned on you why traditional analyses of cultural capital would not be helpful here, and why I had to spend so many pages unfreezing ideas about capital. Taste as just described could not easily be joined to any traditional definition. Under a habitus-based conception of cultural capital, the person portrayed as having good taste in clothes would have to have been born into a family that already had good taste in clothes, where her mother, her grandmother, and even her aunts, also had good taste. She would had to have been immersed, from birth, in dressing right. Otherwise she'd never quite figure out how to dress that certain way. From a restrictive practices point of view, these clothes would have to be expensive and rare and from exclusive outlets. But I did not need to go there; good taste in clothes, among ordinary consumers, requires some money, but not large amounts. From an ethnographic point of view, the account is radically incomplete; I did not say anything about the group she espoused or what her clothes signaled about her cultural identity. That expansion was neither necessary nor possible in this pleasure-based account of mainstream taste.

Finally, and this will be the bridge back to a refounded definition of cultural capital, I stayed ambiguous on one count. Were her taste displays static, showing the same good taste, year after year? Or, might her display have been dynamic, changing in style and extending in range, different this year than last? I didn't say.

In the account given, taste is a personal ability or gift, unevenly distributed in the population. Some people have high amounts of it, most don't. This taste may or may not be specific to a product category. Our exemplar of good taste in clothes may have a well-decorated home or may not; may be an adventurous chef or may not. In other words, we can allow for some people to have a taste gift that extends across categories, while letting others be gifted in only one domain. Cultural capital effective in one domain need not be effective in other cultural domains.

Here is the link that joins taste to capital: when an individual's good taste is dynamic, so that she takes chances, is adventurous, tries and often succeeds at new taste displays, she may be said to amass cultural capital within 
that domain. Her increasing stock of cultural capital fuels new adventures and more pleasing taste displays. A virtuous circle gets rolling, consistent with Bourdieu's later formulation, where capital serves as "both a weapon and the stakes at issue." Taste displays amass capital, and amassing capital fuels new more tasteful displays. By contrast, static taste probably reflects an endowment, which came from the family. Endowments need not be accumulated, or amassed further.

And now at last we come back to blogging. In describing low, medium, and high taste levels I did not mention the Web. I sketched only a vaguely urban setting, and did no more than assume a mass society with a large and prosperous middle class, as could have been found in many parts of the USA in 1990, or 1965; and probably in 1950, and maybe 1920; and in London or Paris, for a few decades further back. None of the clothing or dressing described required the Internet, but only a consumer society, our modern world, whose genesis is teased out in Campbell (1987). The argument in brief: because there was no Internet, not much cultural capital could be accumulated by ordinary people who dressed as described.

The Web alters this world. Now the taste displays of an ordinary person can gain a much bigger audience. The megaphone effect becomes possible. During the baseline period, an ordinary woman could never escape her immediate surroundings; her tasteful dress could never please, outside the circle of family, friends, associates, and workmates. Someone on the street who did turn their head for a second look might never see her again, and could not know her or take repeated pleasure from her tasteful dress. So bounded, the tastefully clothed person could not accumulate cultural capital from her displays of taste. Capital accumulation, before the Web, was a variable-speed motor getting only a trickle of current. It didn't turn over very fast. It could not power much.

With blogging, the motor of capital gets a jolt of electricity. Now the switch can throw to full on, and stay at max. A display of tasteful dress can be seen by thousands, instantly. This mass audience may send accolades and cheers to the blogger by posting comments. Thousands of followers turn the blogger into a taste leader. Exercising leadership, she gains and maintains an audience, and builds cultural capital. New and more adventurous taste displays result. These reinforce leadership, gain more audience, and build further cultural capital.

Remember, it makes no sense to speak of cultural capital except in a context of distinction. To be elevated within a small group of workmates does not provide much distinction; not enough people. But to be distinguished for one's tasteful dress on the World Wide Web, where an audience of thousands can be gained, produces capital.

The new definition of cultural capital highlights the connection between 
taste and aesthetic judgment: a person's capacity to discriminate the beautiful and graceful from the labored and unappealing. In this account, taste has levels, a vertical aspect, and individuals can be sorted by how good their taste is - on their ability to discriminate stylish, fashionable clothing from merely acceptable dress. Cultural capital in the fashion field means the capacity to exercise better taste, to have a higher level of aesthetic ability. But, consistent with the later Bourdieu's dynamic formulation, cultural capital also refers to the stakes that may be gained from that exercise of taste. Fashion bloggers are people who start with some capacity for taste, and proceed to accumulate cultural capital, by the repeated exercise and display of taste, which builds capital, which fuels more and better displays.

This definition of cultural capital, and this depiction of the role of taste in capital formation, differs from the established view in consumer research, which hews to the ethnographic model. Following Holt (1998), taste in contemporary American consumption has been treated as a means to affiliate with a group and to signal that identification. The focus: how taste communities are formed, rather than how an individual can exert taste leadership. As Arsel and Thompson (2011) put it, consumers learn to calibrate their tastes to a field, community, or group with which they identify, to join with others who share the same taste regime (Arsel and Bean 2013). Likewise in Holt (1998), members of the social elite find one another and recognize one another based on shared tastes (for example, for movie directors), even as non-elite and elite members are repelled from one another by differences in taste (regarding a \$22 couch purchase). For scholars in consumer research, taste has meant group-based preference, and not judgment power exercised by individuals, per Gronow (1997). The one sees taste as a device for affiliation, while the other views taste as the capacity to discriminate the laudable from the pedestrian.

Why has past consumer research not teased apart the vertical and horizontal operation of taste? In part, because Bourdieu's own work encompasses both meanings, as seen in this oft-cited remark: "Taste classifies, and it classifies the classifier. Social subjects, classified by their classifications, distinguish themselves by the distinctions they make" (Bourdieu 1984, p.6). The double meaning of distinction corresponds to the double meaning of taste. Taste can be used to draw boundaries (Arsel and Bean 2013), as in, "Do you like what I like?" But taste can also function as a claim of and a denial of worth, as in, "He has a lot of taste . . . all of it bad" (Bayley 1991, p. 77).

Prior accounts in consumer research have successfully imported Bourdieu's account of taste aimed at distinction-between, and developed how taste can be pressed into service as a boundary marker between 
groups, to provide a basis for affiliation and community. The new things consumers do online allow us to examine taste in the service of distinctionover, taste as an agent of social mobility, taste as a resource for clambering up the ladder. It is this kind of taste that enables some fashion bloggers to wield the megaphone.

\section{Goffman on Audiences}

If we had enjoyed clairvoyance, back in 1995, and intuited that fashion blogging would come into existence, what might we have predicted, about the role played by taste in these blogs? In principle, fashion bloggers could have deployed taste either horizontally or vertically. Clothing choicetaste as group preference - can identify the community or subculture to which the wearer belongs: hipsters or clubbers or indie rockers (Elliott and Davies 2006; Goulding et al. 2002). Fashion blogs might have drawn their audience from among consumers pursuing identity projects. The clothing displayed on the blog might have been selected to send a strong signal about the community or subculture to which the blogger belongs (Berger and Ward 2010), and to draw together the like-tasted.

Had fashion blogs fit this model, authenticity would be primary. Holt (1998) argued that consumers with a large stock of cultural capital preferred authentic products. Authenticity implies taste displays that reflect the central tendency of the group (Arsel and Thompson 2011). That is the problem with outsiders and wannabes: their taste displays come across as inauthentic, because deviant or inept. They fail to gain entry because they do not grasp the group taste. Their clothing choice is not judged authentic.

Stepping back, authenticity has been a central value in Late Capitalist times (Johnston and Baumann 2010). Back in 1995, our clairvoyant might have found it plausible, as an anchor to explain the new things consumers might do online, such as fashion blogging. Kozinets et al. (2010), in an early study of bloggers given free products, did find authenticity to be a leitmotif of the dialogue between bloggers and followers, concerning the free cell phone supplied, and the controversy it created.

However, authenticity is not the only core value held by consumers. Arnould and Price (2003) find two threads, woven together, to bind the domain of the cultural arbitrary: consumers care about authentic performances, but also authoritative performances. Authority suggests leadership. Leadership implies the vertical operation of taste, and a very different prediction, from back in 1995, about how fashion blogging might unfold.

Goffman's (1959) work on the presentation of self supports this different prediction. I read him to emphasize taste leadership rather than taste preference. Goffman applied a dramaturgical metaphor to everyday life, 
arguing that in social encounters, people could be parsed into actors and audience, with actors striving to put on a front and convey a persona, and audiences accepting successful actors as they wished to be seen. In Goffman's account, no person is ever authentic in public behavior toward an audience; authenticity, to the extent it is possible, occurs only in the private sphere. To an audience one shows a persona, rather than revealing one's identity. Goffman (1959, p. 58) draws on Simone de Beauvoir for support: "the least sophisticated of women, once she is 'dressed', does not present herself to observation; she is, like ... the actor on the stage, an agent through whom is suggested someone not there, that is, the character she represents, but is not."

Fashion blogging offers an apotheosis of Goffmann's dramaturgical metaphor. Unlike in face-to-face interactions in everyday life, or conversing with known friends on Facebook, a fashion blogger can display a persona that may be far removed from her real self, a persona she can rehearse and rewrite until she gets it right. Display of this persona seems ill-suited to constructing an authentic self. Therefore, blogging must be an authoritative performance (Arnould and Price 2003). But it is a novel kind, insofar as it is an individually sourced rather than collectively underwritten act, and because it cleaves to fashion rather than tradition. Fashion blogging, interpreted in Goffmanesque terms, expands the category of authoritative performances to include a social actor's successful enactment of style - the authority of her taste.

Fast forward to 2010, and clairvoyance is not needed. As it turned out, fashion bloggers - the successful ones we studied - do not blog to affiliate with a community of like-minded consumers. Bloggers do not exhibit taste preferences to draw boundaries. Rather, per Goffman, bloggers exercise taste in the vertical sense, to draw a mass audience of strangers. Gaining a foothold with such an audience launches a virtuous circle, which cycles between taste displays and cultural capital.

\section{EMPIRICAL EVIDENCE}

McQuarrie et al. (2013) describe an empirical study of ten fashion blogs, each of which was launched by an ordinary person, who later gained large numbers of followers. There seemed no point in reproducing here all of the method and results published there. The opportunity, here in this book, lies with introducing ancillary material that didn't make it into the published paper, followed by a brief discussion of key results. The final part of the essay returns to a discussion of the conceptual implications of what we discovered from these fashion blogs. 


\section{Method in Consumer Sociology}

I am publicly criticizing my fellows ... Anyone who does this can expect to have their motives questioned. Readers may wonder whether the author is embittered ... perhaps he has been slighted in the past ... [now] gaining his revenge. Or . . . deeply flawed as a person, a serial troublemaker . . . constantly picking quarrels. (Billig 2013, Learn to Write Badly, p.i)

There are few vetted methods in consumer research; too few, to advance consumer sociology. Vetted means approved by journal reviewers; and as I unpack that point, you'll understand why I led off with that Billig quote.

Publish or perish. Everyone knows that phrase, of course, but not everyone knows the corollary, which governs business academia, and consumer research specifically: publish in the inner circle of peer-reviewed journals, the very best ones, or see your academic career go nowhere. For instance, if I were not already retired, and unconcerned with career advancement, I would hesitate to write this book: no matter how successful, it can do little for my narrowly defined academic reputation, my reputation among colleagues who occupy this corner of academia. Books don't count there.

Only journal publications, and only papers in the most highly selective outlets, where $80-90$ percent of submissions are rejected during the gauntlet of peer review, can advance a scholarly career in business academia and consumer research. Next, the peers, who review submissions for these journals, are people who have already published there, and perforce, published articles that used some method. Reviewers assume that a submission that uses the same method as they did, is probably sound, so that they can proceed to evaluate quality of execution. But if the method is unfamiliar, then all bets are off. Who knows if the results are any good or not? Who can tell whether the unfamiliar method has even been executed appropriately? The consequence: an enormous inertia in favor of established methods. Peer review, as too few recognize, cannot be receptive to innovative approaches.

Although the journal system is hostile to anything new, the established methods in consumer research struck me as especially unsuited to studying cultural capital among fashion bloggers. There are two vetted methods: the laboratory experiment favored by consumer psychologists, and the in-depth interview favored by ethnographers. A laboratory experiment must force out sociological concepts in favor of psychological ideas: it is a stimulus-and-individual-response paradigm. If you have not been initiated into consumer psychology, you cannot begin to imagine the patriotic fervor with which such experiments are endorsed in business academia. Reviewers schooled within that paradigm cannot envision why any serious scholar would ever do anything other than experiment - the One True Path 
to Knowledge (see McQuarrie 2004, 2014 for a more sustained skeptical treatment of such laboratory experiments).

More pertinent to sociology is the ethnographic method, especially, in this context, the netnography pioneered by Kozinets $(2007,2009)$. Before the Web, ethnographers had long engaged in participant observation, living among the natives as it were, and conversing and interacting widely. Alternatively, they interviewed members of a community in depth over time. With netnography, participant observation returned, and researchers began to read blogs and discussion posts, comment back, email questions, and otherwise engage with the online community under study.

By 2010, within the fraction of researchers sympathetic to ethnography, the interview, whether in person or virtual, had acquired the same degree of orthodoxy as the laboratory experiment had got among consumer psychologists. Reviewers could not understand why my co-authors and I did not go out and interview fashion bloggers for this study, or Pinterest users for Essay Three. How can you understand consumers' sense-making, their communally shaped attributions, their psychological processes, their inner life, if you don't interview them? Our retort was: "Who says fashion bloggers are part of a community?" and, "Why do we have to care about their inner life?" To which one reviewer responded, "Community has to come into it!" But authors are in no position to retort to reviewers.

Bourdieu was sensitive to the limits and dangers of interviews in a sociological context. Interviews, like all empirical methods, shape what can and cannot be learned. If you conduct an ethnographic interview, you will tend to discover what ethnographers have historically found when using this tool: that is, community. If you interview people using a more diffuse theoretical perspective - interviews are not the exclusive province of ethnographers - then, given the dominance of psychological perspectives today, your questions will gravitate toward motivation, perception, introspection, and sundry other psychological processes. Neither the ethnographic nor the psychological paradigm is conducive to ferreting out what is properly sociological.

Think about it: if interviews were necessary to understand people, history would be impossible - dead people are among the most difficult to interview. If history can yield understanding, then it must be possible for an analyst to immerse himself in written materials, and come away with an understanding that is not private and unverifiable, but public. Our method was historical, even though the bloggers were still alive. The basic procedure was to sample blogs systematically, and then read copious material in blogs, and about them. My co-authors, who handled this portion of the research, immersed themselves in the blogs, sampling posts from beginning, middle, and end, and moving back and forth in time as they read. 
A consumer sociology can never emerge from psychological laboratory experiments. Any sociology that relies on consumer interviews will tend to revert to ethnography or social psychology. If we are to do consumer sociology, we must be set free to examine documents, and to value the historical analysis of all kinds of documents, whether from blogs, online reviews, or pinboards, or from more traditional sources such as advertisements and correspondence. The tyranny of interviews must cease.

\section{Findings: Blogger Trajectory}

\section{Initial position}

These ten bloggers began as ordinary consumers outside of the fashion system. McCracken (1986) describes the fashion system as composed of the designers and manufacturers of fashion clothing and accessories; the media institutions that promote such clothing in editorials and advertising; and the social elite, especially celebrities, who engage in the vast public relations machine of television and movie roles, special event appearances, and talk-show and gossip magazine placements (compare the gift system defined in Giesler 2006). These are the traditional, professional sources that govern the determination of what is fashionable, also recognized by Bourdieu (Rocamora 2002). None of our bloggers was a fashion insider or professional and no family connections to the fashion system were uncovered. When their blogs launched, these ten individuals were indistinguishable from the millions of ordinary consumers who make up the market for fashion clothing. Ordinary, in this usage, does not mean average or typical, nor does it exclude extraordinary skill, as in the taste displays to be discussed. I mean ordinary in Turner's (2010) sense: neither endowed by family connections nor credentialed by professional or institutional position.

These bloggers may never have intended their blog to be only a personal journal online. The blog titles are rhetorically stylized and replete with complex, allusive forms of wordplay: Fashion Toast, Style Bubble. Mass advertisers use wordplay to attract consumers by aesthetic appeal (McQuarrie and Mick 1996). These bloggers devised blog titles to accomplish the same goal. The rhetoricized titles signal to the prospective audience that aesthetic judgments will be offered.

\section{From personal journal to taste display}

Early posts sometimes give the impression of a consumer who uses her blog as an online journal for personal disclosure (Chittenden 2010; Hodkinson 2007; Kretz and de Valck 2010; Reed 2009; see also Box 1.1): 
just got home from teddys, decided to not go to the after party, we had a great night as it is. me, $\mathrm{z}$ and deb went, paparazzi snapped pictures of us all night long ... they are so clueless ... the gastineau girls were chillin at a table by themselves, still a foreign concept that the mom and daughter party together. random other models and celebs partied really hard ... cant help but love la! time for bed as hollywood continues to party. (BIA 03/25/07)

This post, with its casual focus and lack of attention to spelling and punctuation, describing a night on the town, would pass unnoticed on Facebook or any other social media site. Fashion blogging is undermotivated: almost anything that can be posted on a blog could have been posted on a personal page at a social media site. The key difference: with a blog, you can reach an indefinitely large audience of strangers.

Posts to these ten blogs soon cease to resemble private social media, and evolve toward public displays of taste. Here is an example, from later in one of the most popular blogs.

Found the perfect gray socks while shopping at Uniqlo in Tokyo with my mom/ favorite shopping partner (she's always down to stop randomly to eat and shares my love for finding wearable things in unlikely places). Vaguely sheer and just the right length. This sounds extremely trivial, and sort of is, but I've been looking for something like them forever now. (FT 05/12/10)

This post came to be read by more than 30000 people. It received 174 comments, such as "OMG Rumi, you are my greatest inspiration EVER, you just rock with your amazing outfits and with your breathtaking photos. You are the best style icon EVER." Get past the demotic vernacular, and you see appreciation for the blogger's aesthetic acumen.

Choosing to display gray socks is neither here nor there with respect to taste as distinction-between. These gray socks do not serve as a badge of membership in some group (Berger and Ward 2010). Likewise, the socks are not a signal inviting affiliation with other marginalized youths over against a fictive mainstream (Thornton 1996); the blogger is, after all, shopping with her mom. It is not the display of gray socks per se on a fashion blog, but selection of a particular brand, length, and opacity of gray socks to display - and choosing to pair them with leather shortsthat makes a display of taste leadership. And such displays can be recognized as taste leadership insofar as these attract and hold a large audience (in this case, more than 30000 people).

Consider next the post reproduced in McQuarrie et al. (2013, Figure 1), from another blog. The picture is captioned: "Everything I'm wearing is Vintage, except the Doc Martens. Those babies are fakes, and now the black plastic is peeling away, which I kind of love." The blogger claims to 
be tasteful, by making a risky choice. Who knew that peeling plastic fakes could look good, look right—-be fashionable?

Further insight: "Vintage" is not a stray capitalization error, but the name of a brand of clothing which, according to the manufacturer's website, "is a premier streetwear brand that was born out of the free thinking and creative spirit of the underground music and art cultures . . . [designed for] lyrical wordsmiths, crate digging-vinyl loving deejays ... fed up with the mediocre mainstream brands from malls and major department stores." The Vintage clothing brand lays claim to the heritage of the club, hipster, or indie culture studied by Thornton (1996) and Arsel and Thompson (2011), where real Doc Martens shoes are worn. But by wearing peeling plastic fake Doc Martens, this blogger lays claim to a distinctive personal style. She takes a risk, and invites her audience to judge her: "How does this look?" She exercises taste and makes a public display of it.

These posts build a persona, in Goffman's (1959) terms, an elaborate statement of who the blogger proposes to be: "I am a woman of style. I combine the indie brand of Vintage with the punk brand of Doc Martens yet openly acknowledge I wear fake footwear, while on another day I may pair a real fur hat with a Chanel bag. I make my own fashion statements." Rather than affiliating with a community, the blogger declares her taste: "I think this looks good." What will be judged tasteful, in a concrete instance, is not something "that can be learned in school," to use Thornton's (1996, p. 13) formulation. Rather, audience members with a passion for fashion clothing know taste when they see it. Hence, each taste display by the blogger represents a risk. The blog is an ongoing performance that could bomb at any time (Deighton 1992).

It is because the blogger takes risks, and is judged tasteful more often than not, that she may be said to accumulate cultural capital. Taste as judgment power can't be learned in school, but it can be developed through repeated exercise. A blogger accumulates cultural capital insofar as she succeeds again and again in being judged fashionable, and as a result, develops more and more capacity to take fashion risks and succeed. To use the metaphor of Bourdieu and Wacquant (1992), once a poker player has amassed a large pile of chips, she can play differently than one who has got only a small stake.

Cultural capital accumulates by means of iterated displays of taste that are favorably received; displays which draw, hold, and grow an audience. What elevates the successful blogger? She exercises better taste, reflecting her greater degree of judgment power (Gronow 1997). In the realm of clothing, she makes aesthetic judgments that are both good and adventurous. We know she shows good judgment, when a large number of consumers, exposed to that picture of grey socks with leather shorts, 
viscerally respond, "that is fashionable," or "that is to my taste." With the aid of the Web, a display of taste can win her an audience. In turn, that favorable response increases her capacity to exercise taste, and encourages her to invest in further displays. The blogger acts as a connoisseur with a megaphone.

But the taste display has to be adventurous as well. As Bourdieu (1984, pp.91-92) recognized, there is an element of bluff in taste leadership - it demands flair. Any catalog picture will show attractive people wearing nice-looking clothes correctly combined. But fashion is not a matter of right or wrong according to an explicit and ascertainable standard; fashion is not a dress code (Bayley 1991; Gronow 1997). Fashion doesn't stand still, so that repeating what has already been done cannot secure attributions of fashionable or stylish. To stay within the confines of established selections and combinations of clothing, wins no accolade. To be received as a taste leader, and accumulate capital, the blogger must take risks, such as wearing a Vintage outfit with fake plastic boots, or pairing a real fur hat with a Chanel bag. In fashion blogging, we found consumers exercising verbal and visual connoisseurship, and riding a trajectory toward an economic and social position they lacked at the outset. Here aesthetically discriminating taste judgments lead to an advantageous social position, rather than a privileged social position producing a favored taste judgment.

\section{From community to audience}

These blogs develop over time in a second respect. Just as bloggers begin by sharing moments in their personal life, early in the blog they adopt a community orientation toward others who browse their blog. Initially the blogger is thrilled to receive comments, and answers questions and suggestions with her own comments (Chittenden 2010), or in her next post, as this example illustrates:

Thank you so much for all the kind words and congratulations! I'm going to answer all the questions in that post today, just want to make sure I address them well. One of you mentioned that headbands/scarves would be fun and it inspired me to dig up one of my favorite vintage silk scarves today. Kind of adds a more boho element to the leather skirt. (FT 02/25/08)

Seeming eager to please, bloggers will ask their followers what they would like to see on the blog. Likewise, early in their trajectory, bloggers will provide personal information in response to questions, such as weight, height, and ethnicity, and tell where to find specific fashion items.

The early interaction between blogger and follower is consistent with the treatment of virtual communities in Mathwick et al. (2007), who approach Web-based discussion forums as sites for the accumulation of 
social capital. They define social capital in Putnam's (1995) terms, as a collective possession, and not in Bourdieu's (1986) terms, as connections an individual can use to gain preferment. Mathwick et al. (2007) show how norms of reciprocity play a key role in producing collective social capital within an online community (see also Giesler 2006).

Fashion bloggers begin in the same vein, acting as if the blog were a collective good from which all can benefit, through sharing ideas about fashion clothing, and where all can participate in shaping the content that appears on the blog, per the account of authoritative performances in Arnould and Price (2003). Initially, the blog proceeds as if a virtual community was going to be built, with the blogger acting as one participant among others. But this complex of behaviors soon disappears, as the blogger begins to build an audience.

As her audience grows larger, the blogger's behavior changes. She stops interacting with her followers. She avoids answering questions, ignores suggestions for posts, and refuses to address issues raised in comments. Interestingly, this doesn't bring the growth in audience numbers to a halt. Follower comments become more uniformly positive, as the blogger ignores her followers more and more. As bloggers gain autonomy from their followers' desires and wishes, they appear to be perceived as more worthy of an audience.

An important contribution of early research on online consumer behavior was to establish the existence and reality of virtual communities (Muniz and O'Guinn 2001; Rheingold 2000). It has even been argued that "community is the true 'killer app' of cyberspace" (Jarrett 2003, p. 339). However, this analysis of fashion blogging suggests that community is not the only thing that consumers seek online. In the end, the bloggers studied didn't affiliate with or construct a community-they built an audience.

To this point, consumer research has not considered the value, to ordinary consumers, of becoming an audience rather than joining a community. One explanation comes from the organization theorist Karl Weick (1995, p. 54), who remarked: "when you are lost, any old map will do." Late Capitalist society can be a confusing place, offering the overwhelming freedom to dress any way you please (Davis 1992). Holt (2002) hypothesized that many consumers would buckle under such freedom, and look to "cultural specialists" for guidance (see also Durrer and Miles 2009 on cultural intermediaries). Consumers may be looking for fashion guidance they can't get from professional and institutional sources, such as brand advertisers and other credentialed members of the fashion system (McCracken 1986). Consumers who wander, somewhat lost, provide a ready audience for a peer consumer who has the taste resources to risk 
taking a leadership role. Comments from fashion blog followers support the idea that blogs offer aesthetic inspiration and exemplary taste:

Your dress is amazing, too bad it's vintage, now I can't buy it. But that makes it even more beautiful. With ur chain, clutch, and shoes makes ur outfit perfect! $(S W 06 / 26 / 10)$

I absolutely LOVE your blog. Your outfits are amazing, and it gives me so many more ideas. Thank you! $(S W 06 / 26 / 10)$

What bloggers offer their followers is not a supportive community, or a badge of group membership, but an exemplar of taste. Bloggers engage in an enterprise of distinction-over: in their posts, they show combinations of clothing that may never have occurred to the consumer reading the blog, but which nonetheless strike her favorably. Bloggers establish themselves as better at fashion style than others: leaders, not fellow community members. Taste leadership makes a blog valuable to other consumers, and builds an audience for the blogger.

\section{Findings: Blogger Outcomes}

These fashion bloggers garnered both economic and social rewards. Economic rewards included gifts of branded fashion clothing and other merchandise, paid ad placements on the fashion blog, and paid sponsorship of their blog contests. Other paid assignments included modeling branded clothing, designing clothes and accessories, and writing for publication. Bloggers' social position improves, as they receive invitations to exclusive parties, runway shows, designer open-houses, charity appearances, and mentions in the media. By the time we studied them, these bloggers had gained a role within the larger fashion system unavailable to an ordinary consumer, no matter how involved she may be with fashion clothing.

Any Bourdieusian capital - a status reserved in this book for cultural capital — can be exchanged for economic capital; and economic capital can be exchanged for almost anything else, here in Late Capitalist times. The fungibility of money helps to explain the unruly proliferation of capitals in Bourdieu's work. Since cultural capital can be converted to money, and money can buy social connections, an elite education, and so on, it becomes all too easy to slip into speaking about social capital, educational capital, capital this, capital that. But this tendency has to be fought. If we take seriously the money metaphor underlying cultural capital, then its convertibility into money is a given, and money by definition is fungible. No need to go slapping the label of capital on everything in sight. The task, 
rather, is to tease apart the sources of cultural capital, and trace how it may be leveraged.

These bloggers won an audience by making public displays of taste. Positive response, to their initial displays of taste, stimulated bloggers to develop their taste further. They take risks and make taste ventures. These developments iteratively produce a larger audience and a more favorable audience reaction, which charge the cycle once more. Figure 1.2 depicts this process.

As their audience continues to grow, bloggers come to the attention of promoters in the fashion system, who send economic resources their way, in terms of gifts of merchandise, money for ad placements, and so forth. These resources, which fuel further taste ventures, grow the blogger's audience, which keeps resources flowing, and sets up a positive feedback loop. As their audience grows, bloggers also gain social connections to prominent insiders within the fashion system, which lends bloggers more prominence, which enhances the size of their audience of ordinary consumers, while conveying to this audience that the blogger really is a taste leader (Pham 2011 describes this as a "prominence dividend"). Having and growing an audience makes bloggers valuable to marketers and to fashion insiders alike. The interest of both acts to enhance her audience size, and its approbation for her, which recharges the inner two feedback loops in Figure 1.2.

Countless ordinary consumers, highly involved with fashion, dream of such success, but it is unavailable to all but a few. Our successful bloggers accumulated cultural capital from the small seed with which they began: their ability to make aesthetic discriminations judged suitable by, and novel enough to be of interest to, a mass audience of other consumers. Taste as judgment power fueled these bloggers' success.

\section{Findings: Maintaining an Audience}

\section{Practices of misrecognition}

Once they gain an audience, bloggers appear motivated to hold on to it. Here, these bloggers have an advantage over Vogue and other institutionally sanctioned fashion outlets on the Web, which also compete for an audience. Since clothing is an extension of the self (Belk 1988; Entwistle 2000), believable taste in clothing requires that the blog follower, an ordinary consumer, be able to see herself in the taste displays she encounters on the Web. Can this occur, when the clothes are worn by a supermodel, in a setting impossible for that ordinary consumer to attain? By contrast, a blog follower can look at the taste display of an ordinary consumer, such as the bloggers studied, and believe, "I could look good in that." 


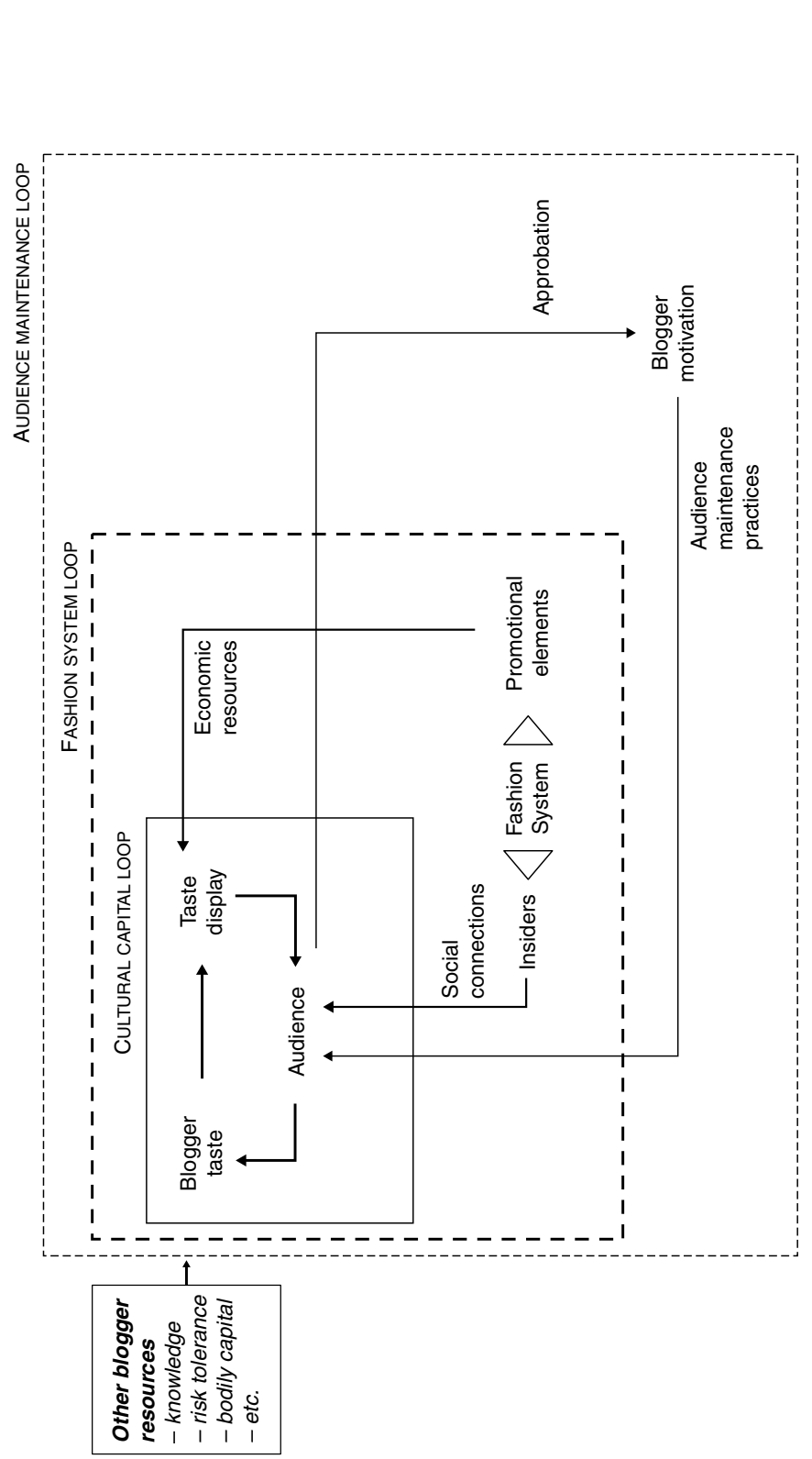

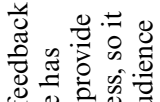

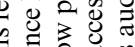
可

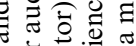

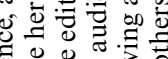
证

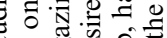
oิ

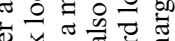
讨 을 물 कo

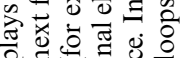
年

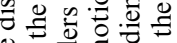

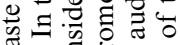

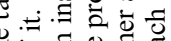

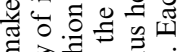

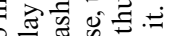

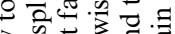
>马口

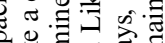
㐘

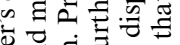

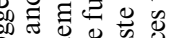
0 范芯.气 㐘的离 율 을 光 过芯芯导

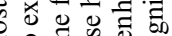
워원

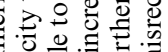
䒕욜 류ㅇㅝㅛ

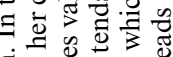
메

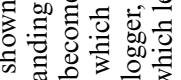
(

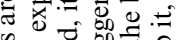

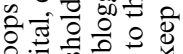

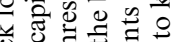
저원 论 ¿ ญ :

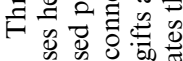

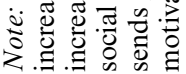


However, once a blogger gains a mass audience and enjoys privileged access to the fashion system, she is no longer truly an ordinary consumer. This poses a threat of loss of audience, and hence of her newly gained position. One solution: practices that deny the existence of boundaries that separate them from followers (Schau et al. 2009; Warde 2005). Two discursive practices fit this description: bloggers feign similarity, and self-deprecate.

Bloggers feign similarity with their followers by referring to mundane and ordinary aspects of their lives that downplay the glamour and rarity of being a fashion insider, with its special access and privileges. Here, for example, the blogger complains about her small closet while posting about her attendance at London's Fashion Week and the gifting of clothes to her by designers:

I leave for Fashion Week on Thursday. I am so excited to be back on The Strand ... probably stumbling all over the place on the impossibly unpredictable cobblestones of Somerset House. Also looking forward to seeing some of the most inspiring people I know. And best yet, I have some exciting clothes coming my way ... So I hope to see you there! By the WAY: Have you noticed the size of my wardrobe in these photos?! Have you seen how painfully SMALL it is? About a quarter of my clothes fit in there, the rest are folded in piles that are forever circling my room: from my desk, to the floor ... and I have even resorted to under my bed. It is a distressing situation! ... One day I'll have the walk-in wardrobe that I actually have vivid dreams about at night. ( $F 02 / 14 / 10)$

Note how the blogger says she hopes to see her followers at Fashion Week, even though the event is attended by invitation only. In this way, she maintains similarity with her followers by deliberately misrecognizing their inability to join her at the event.

A related practice, which again serves to make the blogger appear less distant, is to express self-deprecation and self-ridicule, and to downplay accomplishments. For example, in the Frassy post (above), the blogger states that she will be stumbling all over the cobblestones, implying that she cannot walk in high heels. In other examples, the blogger insults her own appearance, even as she announces her involvement in premier fashion events (McQuarrie et al. 2013).

In self-deprecating, bloggers may mention physical characteristics, bad habits, or embarrassing moments, but deprecation never ventures into the realm of fashion. Bloggers do not ridicule their own taste in clothing. A blogger might say she has a small closet, but she would never say she doesn't know what to pair together from her closet. A blogger might say she stumbles in high heels, but she would never say she had trouble figuring out which brand and color of heels to buy. Self-deprecation and feigning similarity emerge as strategic practices, which misrecognize the blogger's 
actual social position vis-á-vis her followers, consistent with the dramaturgical perspective of Goffman (1959).

Fashion bloggers use strategic practices, of feigned similarity and self-deprecation, to deny boundaries and misrecognize distinction-over. This contrasts with past discussions of cultural capital, in which taste is exercised to exclude others and to enforce distinction-between (e.g., Arsel and Thompson 2011). By contrast, bloggers amass their cultural capital by drawing and holding an audience. To continue this success, bloggers must misrecognize the boundaries that come to separate them from followers. Fashion blogging shows how cultural capital can operate in unsuspected ways, to efface rather than enforce boundaries.

Misrecognition of social position is discussed by Bourdieu (1991). However in his examples, misrecognition takes the form of substitution-up, as when a student in the Paris of Bourdieu's day, and his examiner, misrecognizes his exam performance as due to intellectual merit, rather than to a mere affinity of shared tastes and social background (see the extensive analysis of the grading sheets for the essays used to select students for elite schools in Bourdieu 1996). Fashion bloggers show the reverse form of misrecognition, a substitution-down, in which they deny their factually privileged position relative to followers.

\section{Misrecognition and authenticity}

Authenticity has been widely studied in cultural sociology as well as consumer research (see Chapter 2 in Johnston and Baumann 2010 for an integrative review). As a rule, people seek authenticity in the uncommon, and in opposition to the mainstream (Thornton 1996). Thus for Holt (1998), to seek after authenticity is to avoid market-constructed meanings, and to resist mass culture or try to mask its influence (Beverland and Farrelly 2009; Campbell 2005; Rose and Wood 2005). Arsel and Thompson (2011) similarly find that greater amounts of cultural capital help hipster consumers to reject meanings imposed by mainstream culture, and preserve the authenticity of their taste preferences.

This description of authenticity presents a puzzle. These successful fashion blogs were replete with commercial endorsements of mainstream goods. Why do consumers not reject and disdain these blogs as inauthentic, as happened to some of the bloggers studied in Kozinets et al. (2010)? Each fashion blog contains many commercial messages and each photo is captioned with a list of all the brands worn, down to the nail polish. Many brands are endorsed, including retailers and online shopping sites; most are well-known, mainstream fashion brands, rather than artisanal or craft brands. Often, the items displayed on the blog are sponsored or gifted by fashion manufacturers, as freely admitted 
by bloggers. Nonetheless, the response of blog followers remained very positive.

Why does the commercialization rampant on these fashion blogs not produce the jarring effect found by Kozinets et al. (2010)? Perhaps authenticity, in Holt's (1998) sense of rejection of marketplace meanings, is only central when a blog presents itself as a personal blog, an online journal where identity work will be performed (Chittenden 2010; Parmentier and Fischer 2011). Marketing efforts, when these intrude upon personal blogs, do transgress. Successful fashion blogs represent something else: a public display of taste. Fashion products and their brands are intrinsic rather than extrinsic to the taste asserted. The appearance of free gifts on the blogs ratifies the blogger's taste leadership, rather than violating trust.

Another explanation stems from the effective misrecognition which bloggers practice. If followers live vicariously, through consecrating the blogger (Bourdieu 1991), then when the blogger receives invitations, gifts, and deals, these perks only reinforce the consecration. That is, unusual privileges and a bounty of gifts confirm the blogger's taste leadership. Consumers accept overt marketing in these blogs without scorning the lack or loss of authenticity.

\section{DISCUSSION OF FINDINGS}

\section{Bourdieu on the Web}

In the first part of this essay, I pruned and redirected Bourdieu's ideas, to tie cultural capital back to financial capital: a liquid thing, an asset that consumers can invest, risk, and accumulate (Bourdieu and Wacquant 1992). Under this dynamic account, fashion bloggers act as cultural capitalists, amassing capital as they make venturesome displays of taste. Once these taste displays have acquired a large enough audience, bloggers can convert their cultural capital into economic and social resources, as the established fashion system begins to assimilate them. Once they join the system, audience acquisition becomes self-reinforcing, as positive feedback loops leverage institutional elements of the fashion system, a circuit kept open by bloggers' practices of misrecognition.

I've depicted the Web as a causal factor that midwifes new forms of consumer behavior. Past consumer research has tended to treat the things consumers do online as analogues of what they do offline, and to view the Web as only a new location. Thus, researchers have asserted that marketplace communities can be established online same as offline (Muniz and O’Guinn 2001), norms of reciprocity govern online communities same 
as offline (Giesler 2006; Mathwick et al. 2007), and consumers' postings online correspond to word of mouth offline (Kozinets et al. 2010).

By contrast, a focus on consumers' new-found capacity, courtesy of the Web, to acquire a mass audience, suggests that something new and different occurs there. Ordinary consumers could not gain such an audience before the Web. There is no offline equivalent of a verbal-visual blog, a Yelp restaurant review, or user-curated images published on Pinterest. Before the Web, only professionals holding an institutional position could publish their writing or images. Ordinary consumers were confined to their immediate social networks and communities; they could not grab the megaphone and acquire a mass audience of strangers for their acts of consuming. As a consequence, the value some consumers place on acquiring a large audience of strangers, and the value other consumers place on being part of such an audience, had not been glimpsed. The megaphone effect, combined with ideas from Bourdieu and Goffman, makes these new consumer acts visible and comprehensible.

The distinctiveness of the megaphone effect, as manifest in fashion blogging, may emerge more clearly through a contrast with earlier studies of online consumer behavior by Schau and Gilly (2003) and Giesler (2006). In their study of personal websites constructed before blogging had diffused as a widespread practice, Schau and Gilly found consumers who undertook to communicate to an unknown public without institutional support, in rough parallel to what we found in fashion blogging. However, there was a key difference: the websites in their study were ultimately intended to reach individual unknown others, in order to set up a dyadic interaction; as, for instance, with future romantic partners or potential employers. Giesler's (2006) study of peer-to-peer file sharing through Napster defines a gift system, parallel to what we, following McCracken (1986), refer to as the fashion system. For Giesler a gift system is not merely a set of dyadic gift-giving relationships, or a bounded community of reciprocal give and take, but an overarching socio-cultural structure, one that rests on, and provides an opportunity to demonstrate, social distinction (cf. Bourdieu 1980, pp.98-101). Likewise, we represent the fashion system as a locus where ordinary consumers, by means of the Web, can attain distinction. The key difference: taste leadership played no role in the file-sharing gift system studied by Giesler (2006), whereas here, it is taste that drives bloggers' distinction.

My adaptation of Bourdieu highlights the role of taste in consuming, especially online, even as it shifts the emphasis away from existing theories of how taste operates. In the past, consumer researchers focused on the horizontal operation of taste: the ways in which taste preferences group consumers together and serve to divide an Us from a Them: 
distinction-between (Lamont 1992). This study, of how mass audiences are built on the Web, shifts the focus to the vertical operation of taste: the way that judgment power - the capacity to make aesthetic discriminations that can win an audience-enables a select few consumers to distinguish themselves as above the rest. When we apply a sociological lens, and put aside the ethnographic lens, we discover that consumers can place as much value on achieving prominence, as securing an authentic identity (Goffman 1951, 1959).

\section{Ideology of Giftedness}

In adopting Gronow's (1997) definition of taste, based on judgment power and aesthetic discrimination, in one respect I deviated from Bourdieu's position. To be more blunt, there is one area where I rejected Bourdieu's view, rather than trying to retrieve or refashion it. This rejection is teased out next.

Throughout his career, Bourdieu was hostile to what he called the ideology of giftedness (Bourdieu 1990, p. 109): the supposition that aesthetic ability or good taste was inborn, a personal gift independent of the social position and historical context of the bearer. Bourdieu also rejected the related assumption, that objects themselves could be beautiful, tasteful, or fashionable, as opposed to being deemed such by culturally and socially situated individuals. In Bourdieu's experience, to assert good taste often meant only to assert the taste of the ruling class, taste judgments legitimated by the social position of the person doing the judging. As Gronow (1997) notes, this position is unsustainable, given the fluidity and mobility of modern consumer society, and is peculiarly unsuited to the sphere of fashion, where mutability is of the essence.

We can nonetheless be sympathetic to Bourdieu's project, and his reasons for inveighing against the ideology of giftedness. As developed earlier in Box 1.6, sociologists are keenly aware of, and vigilant against, the tendency to naturalize, and thus misrecognize, matters that belong to the domain of the culturally local and arbitrary. Most attributions to human nature have to be looked at with suspicion, once this sociological mindset has been grasped. What bothered Bourdieu, I believe, was the attitude of Enlightenment Rationalists (never absent from France) and socially well-off aesthetes - who might be one and the same-in which they knew, really knew, that this one is beautiful and that one is humdrum, this shows taste and that does not, this has aesthetic value and that does not. "Balderdash!" 14 Bourdieu might have spluttered. "What you perceive to be your gift of discernment is nothing but your social position projected onto compatible objects. You elevate supposed art over supposed 
kitsch to elevate yourself over others." Bourdieu had a fractal model of the social and aesthetic spheres, in which the structure of the one was projected and reprojected onto the other, almost as if two funhouse mirrors were arranged face to face. Certain objects were perceived by certain refined people as more refined than the humdrum objects esteemed by the common sort who lacked refinement. This hermetic circle naturalized taste as a gift, possessed by a special few of the better sort of people.

But in rejecting the idea of a personal gift for aesthetic discrimination, a gift of judgment power, a beautiful baby got thrown out with the dirty gray bathwater. Bourdieu's efforts to expose the misrecognition, of social position as aesthetic judgment, called into question the idea that anyone could have better aesthetic judgment than anyone else. Consistent with the Copernican and Darwinian spirit of modernity, this skepticism leads inevitably to Boaz's ethnographic position: no one can have good taste across groups - no one cultural product can be judged better than some other culture's product - even as everyone has taste within their group of affiliation, can recognize and celebrate objects consecrated in their own group or culture. From the rejection of giftedness it is a short step to the rejection of all taste judgments as culturally arbitrary, on a par, a matter of the group with which you identify; nothing more to be said.

With the post-Kantian demise of the idea that taste hierarchies are universal, the horizontal operation of taste came naturally to the fore, in consumer research as elsewhere. Taste was made relative and particular to communities and subcultures. Nonetheless, selectivity, exclusion, and hierarchy continued to operate in spheres such as clothing. Mainstream mass society endured and flourished, and aesthetic judgments about consumer goods continue to be made and contested there. I've argued that tasteful, in the vertical sense, now consists of intuiting what might be to the taste of a mass audience of involved peers. Taste in fashion can once again be treated as a gift that a select few consumers possess. By means of the Web, these select few can leverage that gift to acquire cultural capital, and convert this capital to social position and economic resources.

What distinguishes the megaphone effect is the absence of institutional mediation. These fashion bloggers acquired their initial audiences on their own. This separates the megaphone effect from reality television on the one hand, and fast fashion on the other (Ferdows et al. 2004; Crane and Bovone 2006). In fast fashion, a clothing manufacturer-an institution - seeks out fashion innovations on the street among the people, and puts these street fashions into production. As with reality television, originally demotic elements get picked up and presented to a mass audience; but in each case media and manufacturing institutions retain control. Fashion blogging, online reviewing, and user-curated 
images represent something different. Here, institutions are only ancillary, not determinative.

Some consumers have the gift of good taste. That gift explains why some fashion bloggers gain a mass audience. Whether by nature, nurture, or both, some people go beyond involvement with the clothing category to demonstrate good taste-judgment power, aesthetic discrimination. The presence of this gift may bear some relation to family social position; I'd wager that most people who show judgment power for clothing enjoy at least some discretionary income. The argument stands, as long as judgment power does not vary in lockstep with increasingly advantaged social position.

The Web changes things. The gift of taste can now be leveraged outside an immediate circle. The leverage is provided by the megaphone effect: the newly available possibility of reaching a mass audience, without first having to gain a favored institutional position. Before the Web, no ordinary person, acting on their own behalf, had much chance to gain a mass audience. This is new.

\section{LIMITATIONS}

A more extensive discussion of limitations appears in McQuarrie et al. (2013). Here I only touch on some limitations of the empirical work reported, to begin the transition to the next essay, which will switch focus, from fashion clothing and blogging, to restaurants, Yelp, and online reviews.

The taste leadership displayed in the fashion blogs we studied, and its role in explaining how they acquired a mass audience, may not generalize to explain the success of other kinds of blogs, such as technology blogs, or even other kinds of fashion blogs, such as those undertaken by men, or originating outside the developed Anglo-Saxon societies where our blogs were situated (Pham 2011). Nor need taste leadership be the only explanation for the success of young female bloggers, some of whom may blog in pursuit of an identity project, or as a means to affiliate with a subculture (Scaraboto and Fischer 2013).

Likewise, we studied blogs at a particular juncture in the diffusion of Web technologies. Whether blogging, on fashion or any other topic, will continue to let ordinary consumers grab hold of the megaphone, is unknown. The megaphone effect seems likely to endure for awhile; but the routes by which consumers get hold of that megaphone may shift or evolve. 


\section{Not All Goods Are Taste Goods}

The rule laid down in this essay has been: if no exercise of taste, then no accumulation of cultural capital. To back up this rule I had to define taste, in the consumer sphere, narrowly. Taste only pertains where, per Thornton (1996), "things that can't be learned in school" are central. When knowledge that can be learned in school provides expertise, or when professional and institutional experience provides knowledge, taste ceases to be pertinent. I have tried to preserve cultural capital for consumer research by making it specific to taste, and drawing tight limits around the sphere of taste. The heart of the strategy: separate taste from knowledge and skill. The stakes are high. Wherever Becker's (1993) idea of human capital, derived from the exercise of knowledge and the practice of skill, can explain consumer behavior, there is no point in bringing in cultural capital (Ratchford 2001). Beauty dare not tread where Truth makes his bed.

Within this first limit, a second may be glimpsed: not all taste judgments produce cultural capital. Taste is present wherever an aesthetic discrimination can be made; but the exercise of taste can only accumulate cultural capital when preferment is possible. That is, taste leadership, rather than simply taste clustering, must be possible, before cultural capital comes into play. In this study, taste leadership meant acquiring a mass audience; other routes may exist.

A third limit confines the applicability of a dynamic conception of cultural capital. I do not deny the continued pertinence of a static notion of cultural capital, wherein large amounts of it come into your possession as a family endowment, as a result of institutional position, or from education. High levels of taste - taste ratified by large numbers of social peers - can still be produced by birth, or by acquiring a favorable social position. But the reverse sequence, in which the exercise of taste leads to a higher social position, is now possible, courtesy of the Web. Our fashion bloggers, who acquired a mass audience online, supply an anchor case for this trajectory.

Pulling together these threads, a dynamic conception of cultural capital should be fruitful in three broad categories of consumer goods: (1) fashion clothing and accessories; (2) food, including restaurants (Johnston and Baumann 2010); and (3) home décor, including any visible aspect of the abode, whether interior or exterior (Arsel and Bean 2013; Lynes 1980 [1955]). The cultural arbitrary governs these domains (Bourdieu 1984, p.78). These three categories appear often in post-Bourdieusian scholarship on taste (Bayley 1991; Falk 1994; Gronow 1997; Warde 1997). A question for future research is whether taste operates more widely in consumer behavior, and if so, where. Although food, fashion, and home 
décor are good places to start, for exploring the role of taste leadership in consuming, there may be yet others.

\section{Consumer Culture, Consumer Sociology}

Consumer researchers have learned much about the pursuit of identity (Arnould and Thompson 2005; Parmentier and Fischer 2011), the role of community in supporting identities formed in opposition to the mainstream (Thornton 1996), and how authenticity can be claimed or disputed (Arnould and Price 2003). Less is known how consumers go about improving their social position, or pursue mainstream success, or gain preferment outside of an institutional path. This research suggests that many consumers wish to join audiences, not just participate in communities, that a select few ordinary consumers desire an audience for their consuming, and that both actions flourish online.

Muniz and O'Guinn's (2001) innovative treatment of community among consumers marked a swing of the pendulum in social history. As originally conceived by German sociologists such as Tonnies, the marketplace was portrayed as the antithesis of community, and even, the agent of its destruction. Following Muniz and O'Guinn, researchers have explored how consumers construct marketplace communities, including virtual communities (Mathwick et al. 2007). That work has supplied a corrective to individually centered and purely psychological accounts. But under a sociological lens, consumers do not only affiliate with communities - they also seek positions in society, vis-à-vis a mass of strangers. These positions not only shape, but are shaped by, and even attained by, consuming. Courtesy of the Web, a new kind of social position has emerged: that of the taste leader who takes hold of the megaphone, builds an audience for her consuming, and gains a position she didn't have to start.

But the megaphone effect is not the only new thing on the Web.

\section{NOTES}

1. Some sentences in this essay appeared previously in McQuarrie et al. (2013); the duplication is greatest in the "Findings" sections. Before and after, the material has been largely rewritten and greatly expanded.

2. The idea of specifying a baseline period, and locating it then, comes from me, not Turner.

3. Yes, I know that the original phrase was "to the manor born." I want to highlight the pun.

4. Much later, in the epilogue, I'll challenge the supposed distinction between metaphor and theory; but here, I conform to ordinary usage, in which the word metaphor has to be prefaced by a diminutive like mere. 
5. Another argument for getting rid of (Bourdieusian) social capital, in the service of pruning and strengthening the important idea of cultural capital: too many other theorists have laid claim to the phrase, and mean something quite different by it than did Bourdieu. In the United States, social capital is most famously associated with Putnam (1995). He is not alone; to learn about other claimants to ownership of the term, see Baron et al. (2000). Bourdieu is unusual in making social capital the possession of an individual; other traditions locate it outside of individuals, in the collectivity. In consumer research, see Mathwick et al. (2007). In sociology, see Erickson (1996) and Lizardo (2006).

6. This diagnosis may be specific to the small corners of academia I have occupied: a business school, and the interdisciplinary association of consumer researchers, most but not all of whom are located in business schools. Whether historians or sociologists encounter this mindset in their departments and associations, I cannot say.

7. To describe, in English, phenomena associated with pretension and status claims, there are an astonishing number of words borrowed from French: parvenu, arriviste, poseur, nouveau riche, jejune, déclassé. I'm not sure why that is.

8. I don't think Goffman intended quite such a restricted meaning for restrictive practice, but I find it convenient to assign him thus, the better to tease out the differences between the intuitive, quite specific application of restrictive practice, and the broader applicability of Lamont's idea of drawing boundaries that include as much as they exclude.

9. This ideology has able exponents, but has never appealed to me. To be frank, as a favorably dated Baby Boomer, born into the middle class, I've lived too well in material terms, while rising too far in what has seemed a very stable academic hierarchy, to be able to believe that things have fallen apart and the center cannot hold. It's perhaps an easier ideology to adopt if you have been a maltreated female professor in the Humanities, perhaps an adjunct paid a pittance, or at least a person of color, rather than, like me, a white male living a life of plenty in the USA.

10. Of course, much brand advertising is directed at climbing this steep hill, and infusing cultural identity into products that carry none (Marchand 1985).

11. Major kitchen appliances are an interesting liminal case, since they are machines but also home décor.

12. A complicating factor: I don't have high levels of taste in any of the domains I will be discussing; surely not clothing, although maybe home décor, since I was designing a house as this was written. But if taste is real, and not a habitus of class or a function of group identification, my lack of it should not produce insuperable problems for this scholarly study of it.

13. This dances around a philosophical elephant in the room, that has caused a ruckus since at least Kant; see Gronow (1997) for an illuminating discussion.

14. Bourdieu would have used some pungent French phrase, of course, but I'm writing for an Anglo-Saxon audience. 